\title{
Las relaciones de los monarcas navarros con la aristocracia de ultrapuertos hasta 1328*
}

\author{
Relations between the navarrese monarchs and the aristocracy \\ of lower navarre until 1328
}

\author{
Susana Aparicio Rosillo**
}

\begin{abstract}
RESUMEN
Las tierras navarras de Ultrapuertos se encontraban confrontadas a una realidad especialmente compleja, puesto que representaban una zona de fricción entre intereses navarros, ingleses y franceses. Sin embargo, las familias nobles que habitaban este espacio mantuvieron un discurso equilibrado frente al poder regio navarro. Por un lado se aseguraron de que sus privilegios se mantenían intactos y que las injerencias del monarca en el territorio fueran lo más limitadas posibles. Por otro lado, escogieron cuidadosamente sus lealtades, cuando no bascularon entre varias fidelidades distintas. Mientras tanto, no dudaban en formar parte ellos mismos del engranaje del poder real navarro, formando parte del ejército o de los cuadros ejecutivos del reino, lo cual evidencia una elaborada estrategia de pervivencia y adaptación de estas elites nobiliarias ultraportanas.
\end{abstract}

\section{PALABRAS CLAVE}

Ultrapuertos, Navarra, frontera, aristocracia, poder efectivo, oficiales del reino.

\section{ABSTRACT}

The lands of Lower Navarre (also known as Ultrapuertos) were immersed in a complex reality as they were located in a zone of friction between the Navarrese, the English and the French. Nevertheless, noble families that inhabited this space kept a delicate balancing act with respect to the royal Navarrese power. On the one hand, the aristocracy managed to maintain their privileges and avoided meddling by royal forces in the territory. On the other hand, they carefully chose their loyalties, often moving from one camp to the other. Meanwhile, they did not hesitate to form part of the royal Navarrese power structure within the army or the upper echelons of the administration of the Kingdom. This attests to the survival strategy and adaptability of the nobility of Lower Navarre.

\section{KEY WORDS}

Lower Navarre, Kingdom of Navarre, Frontier, Nobility, Effective Control, Royal Officials.

\footnotetext{
* Fecha de recepción del artículo: 2013-07-01. Fecha de aceptación del artículo: 2013-10-28

** Universidad Pública de Navarra. C.e.: susana_apar@yahoo.es.
} 


\section{INTRODUCCIÓN ${ }^{1}$}

El objetivo general de este trabajo es mostrar el asentamiento progresivo de la autoridad de los monarcas navarros en las tierras de la vertiente norte del $\mathrm{Pi}$ rineo denominadas como Ultrapuertos, a través de su relación con la aristocracia autóctona, desde el asentamiento de los navarros en estas tierras hasta la llegada al trono de la Casa de Evreux tras la muerte del último rey Capeto directo. Ésta preludia los luctuosos eventos de la Guerra de los Cien Años, que cambiaron profundamente la morfología y la estructura de los señoríos en el sudoeste francés.

La aristocracia ultraportana se encontraba profundamente mediatizada por el espacio fronterizo en el que se había asentado. Este estudio pretende desvelar la instrumentalización por parte de este grupo social de su propia situación precisamente como un factor de colaboración y promesa de lealtad hacia el soberano navarro, a la vez que conseguían integrarse en los cuadros administrativos y militares del reino. Esto contribuyó por su parte al asentamiento del poder territorial del monarca navarro más allá de los Pirineos. Otro punto a tener en cuenta es que, a pesar de su imbricación el aparato administrativo navarro, los aristócratas ultraportanos declinaron establecer lazos duraderos de lealtad con los grupos aristocráticos navarros peninsulares, inclinándose hacia alianzas con las familias del entorno, aunque se encontraran en la zona controlada por el monarca inglés en su calidad de duque de Aquitania².

En efecto, Ultrapuertos se localiza en un espacio de fricción entre los grandes poderes europeos medievales. En la costa labourdina imperaba el rey de Inglaterra al ostentar también el título de duque aquitano, mientras que hacia el este se situaban los vizcondes de Béarn, con su tradicional alianza aragonesa y posterior acercamiento al mundo inglés. Por su parte, no se debe perder de vista que la estrategia política navarra a partir de la llegada al trono de la dinastía de Champaña en 1234 se encontraba íntimamente ligada a la de la familia real francesa.

De este modo, esta confluencia en un mismo espacio de tantos intereses enfrentados generó a su vez una realidad compleja que mediatizaba el comportamiento de la aristocracia local. Ésta mantuvo un discurso que podríamos calificar

\footnotetext{
${ }_{1}$ Abreviaturas utilizadas: ADPA= Archives Départementales des Pyrénées-Atlantiques; $A G N=$ Archivo General de Navarra; $A M B=$ Archives Municipales de Bayonne, TNA= The National Archives (Londres); AVRN= Acta Vectigalia Regni Navarrae Documentos financieros para el estudio de la Hacienda Real de Navarra, Serie I: Comptos Reales.

${ }^{2}$ Este artículo ha sido redactado gracias a una ayuda posdoctoral de movilidad y atracción del talento investigador, modalidad outgoing, incluida en Plan de Formación y de I+D 2010/2011 del Gobierno de Navarra y en el marco del proyecto de investigación del Ministerio de Ciencia e Innovación «Espacios de la memoria. Los Cartularios regios de Navarra: Construcción y expresión del poder» (HAR2010-21725-CO3 subproyecto 3 ).
} 
como de equilibrio inestable ${ }^{3}$. Por un lado, se encontraba la defensa de su poder territorial - sin menoscabo del respeto a la autoridad regia, al menos nominalmente- representada entre otras cosas a través de su constante implicación en conflictos privados regionales y por el doble homenaje prestado en ocasiones simultáneamente al monarca inglés y al navarro. Por otro lado, es posible detectar a su vez su entrada progresiva dentro de los cuadros de la administración y su proliferación dentro del aparato militar navarro durante los conflictos que jalonaron estos espacios fronterizos durante los siglos XIII y XIV. De esta manera la aristocracia ultraportana empezó a ascender en la escala social peninsular navarra sin dejar de estar centrados en sus territorios patrimoniales ultrapirenaicos, lo cual se puede detectar precisamente a través de la ausencia de lazos familiares o de lealtad con las elites navarras peninsulares —al menos durante esta época- Todo ello se desarrollará en líneas posteriores, utilizando sobre todo las fuentes contables del Archivo General de Navarra, que narran en una secuencia cronológica constante tanto la ascensión a estos cargos de las elites ultraportanas como la vigilancia que ejercían los agentes reales sobre ellos para impedir los conflictos privados o las transgresiones jurisdiccionales que tuvieron lugar en estos territorios convulsos ${ }^{4}$, además de las fuentes inglesas relativas a la zona compiladas en los llamados Gascon Rolls.

Antes de pasar a analizar las cuestiones propuestas, resulta necesario realizar una breve contextualización, estableciendo el marco geohistórico en el que abordamos las actuaciones de estos grupos aristocráticos ${ }^{5}$. Las tierras de Ultrapuertos representaban un espolón proyectado al otro lado de los Pirineos. Esto es, el reino de Navarra contaba desde finales del siglo XII con un espacio ultrapirenaico que se adentraba en mitad de las parroquias controladas por el rey duque inglés, entre

${ }^{3}$ En una definición puramente cinética, un objeto se encuentra en equilibrio cuando las fuerzas que actúan sobre él se compensan entre ellas. Sin embargo, este equilibrio puede ser inestable, en el momento en que dicho objeto, al ser perturbada dicha situación de equilibrio, no regresa a su posición inicial, sino que se mueve y se aleja. De ahí que hayamos escogido esta expresión para definir las actitudes de los grupos aristocráticos ultraportanos, cuya estabilidad se veía constantemente amenazada, pero que a la vez tomaban esta situación como una oportunidad para moverse y utilizarla en su propio beneficio.

4 Estos registros contables se encuentran transcritos bajo la dirección de Juan Carrasco en los sucesivos tomos de la colección Acta Vectigalia Regni Navarrae (AVRN) y se utilizarán constantemente para esta investigación (CARRASCO, J.; MIRANDA, F.; RAMÍREZ, E.: AVRN, Registros de Teobaldo II: 1259, 1266, Tomo I, Pamplona, Gobierno de Navarra, 1999 a CARRASCO, J.; BEROIZ, M.: AVRN, Registros de la Casa de Francia. Carlos I el Calvo: 1328, tomo XII, Pamplona, Gobierno de Navarra, 2009).

5 Somos perfectamente conscientes de la importancia que revestía, sobre todo en un marco de longue durée, las relaciones entre el reino de Navarra y las tierras labourdinas bajo dominio del monarca inglés, y que ciertamente los movimientos políticos de este último tienen su repercusión sobre los territorios ultraportanos. También se comentará en líneas posteriores la importancia de Bayonca como polo comercial y una salida al mar para los territorios navarros. Sin embargo, este trabajo se centra en los valles del norte del Pirineo que se encontraban directamente bajo el dominio del rey de Navarra como muestra la ilustración siguiente. Esto es, Cisa, Baigorry, Ostabat y Lantabat, el valle de Arberoa, las tierras de Mixa y, eventualmente, las parroquias de los señores de Agramont localizadas en la ribera del Adour. 
el Labourd y el vizcondado de Soule, avanzando hacia la ribera del Adour, como se puede ver en el mapa que aparece a continuación.

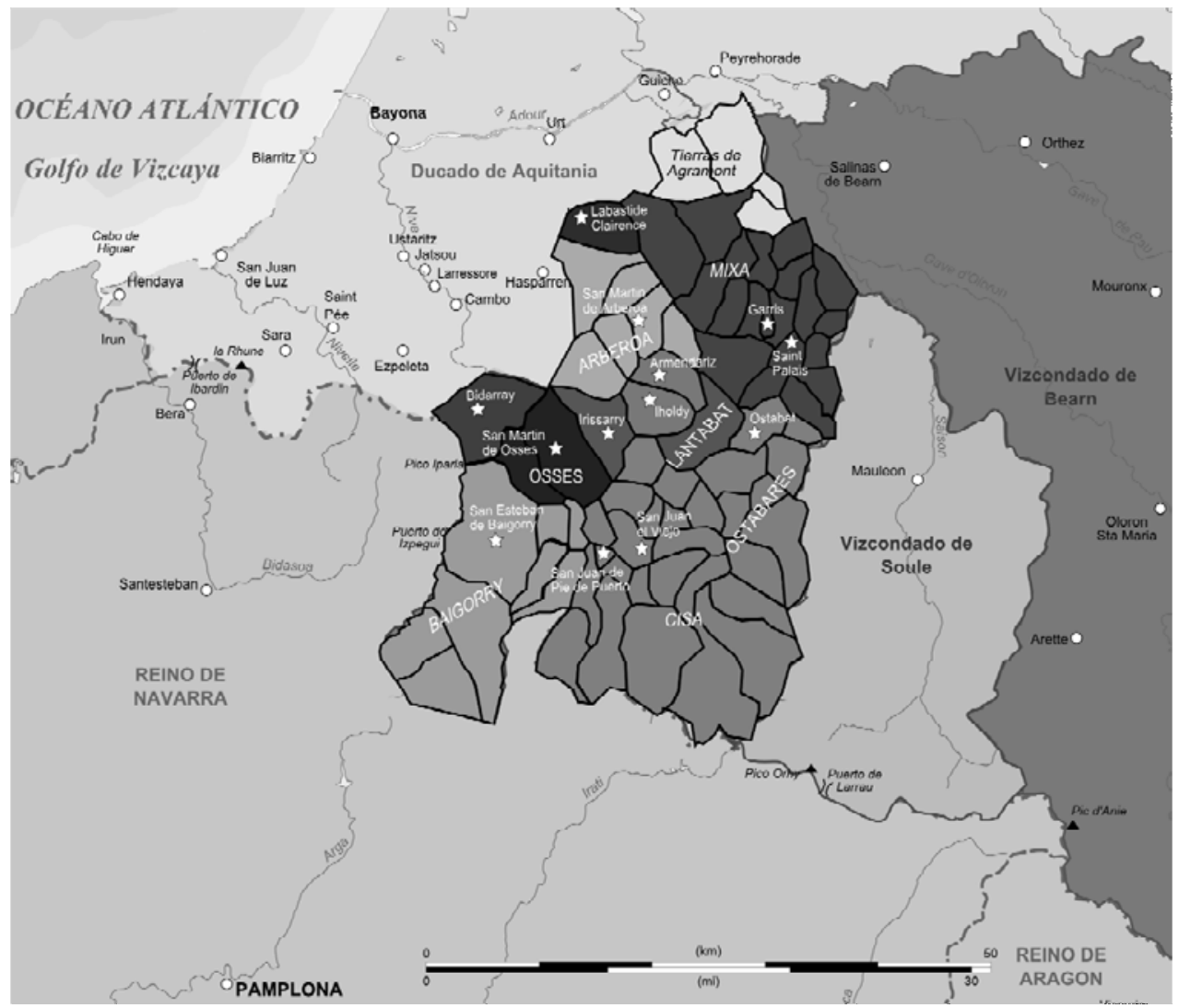

Situación de las tierras de Ultrapuertos. (Fuente: elaboración propia.)

Los espacios fronterizos como el que ahora nos ocupa destacaban por su carácter dinámico y flexible, que ha sido señalado de forma reiterada en las obras clásicas $^{6}$. De este modo, lo que tratamos de destacar en este estudio es el sola-

${ }^{6}$ Así lo afirma TURNER, F. J.: The frontier in American History, ejemplar electrónico http://www.gutenberg.org/files/22994/22994-h/22994-h.htm\#Page_39, consulta 12/04/2013, p. 38, aunque para el estudio de la frontera se pueden citar también las conocidas obras de BARTLETT, R., y MACKAY, A. (eds.): Medieval Frontier Societies, Oxford, Oxford Univ. Press, 1992 en la que hay un artículo de R. BURNS precisamente sobre el significado de la frontera, o el libro que MACKAY, A., dedicó a la Península ( $L a$ España en la Edad Media. Desde la frontera hasta el Imperio Madrid, Cátedra, 1995), o los estudios de POWER, D. : «Frontiers: Terms. Concepts, and the Hístorians of Medieval and Early Modern Europe», en POWER, D.; STANDEN, N. (ed.), Frontiers in Question, Nueva York, Palgrave Macmillan, 1999, pp. 1-31 o BEREND, N.: «Medievalists and the Notion of the Frontier», The Medieval History Journal, 211 (1999), pp. 55-72 y TOUBERT, P.: «Frontière et frontières: un objet historique», en Castrum 4. Frontière et peuplement dans le monde méditérranéen, Roma-Madrid, Casa de Velázquez-Ecole Française de Rome, pp. 9-17; entre otros. 
pamiento de varias esferas de poder diferenciadas que, haciendo una analogía matemática con la teoría de conjuntos, creaban para estos espacios un punto de intersección en el que los elementos comunes de dichos poderes se diluían e incluso se entrecruzaban. Esta situación generaba una complejidad añadida a los vínculos que establecía la aristocracia presente en dicho espacio, y por tanto también en cuanto a las instituciones que lo controlaban, que se veían impelidas a emitir directrices específicas y nombrar cargos destinados a regular estos territorios, más susceptibles a una cierta permeabilidad, favorecida por la pluralidad de intereses en juego ${ }^{7}$.

Esto generaba además un escenario de fricción entre poderes casi continua, provocando una casuística conflictiva que por definición resulta común a la mayor parte de los espacios fronterizos ${ }^{8}$. En concreto, las tierras ultraportanas se vieron envueltas constantemente en pequeñas ofensivas privadas, a la vez que se enrolaban también en conflictos a mayor escala, como los ocurridos durante los enfrentamientos anglo-navarros de 1244 y 1266 o, más tarde, en la Guerra de los Cien Años. La respuesta del poder regio pasaba también por intentar constituir y mantener en la zona un sistema de defensa efectivo frente a eventuales ataques, e intentar controlar - aunque con escaso éxito, como se verá más adelante- la violencia privada de estos grupos aristocráticos ${ }^{9}$.

Con respecto a la frontera pirenaica se pueden citar entre otros los trabajos de REGLÁ, J.: Francia, la Corona de Aragón y la frontera pirenaica, Madrid, CSIC, 1951; LAMBERT, E.: «Les relations entre la France et l'Espagne par les routes des Pyrénées», en Mélanges D. Faucher, tomo I, Toulouse, 1948, pp.319-328 los artículos de MITRE, E.: «Cristiandad medieval y formulaciones fronterizas» en MITRE, E.; GARCÍA CÁRCEL, R., LUCENA, M.; et al.: Fronteras y fronterizos en la historia, Valladolid, Universidad de Valladolid-Instituto Simancas, 1997, pp. 9-62; BAZZANA, A., et al.: «La frontière dans l'Espagne médiévale», en Castrum 4. Frontière et peuplement dans le monde méditérranéen; pp. 35-59; y MARTíN DUQUE, Á. J.: « Definición de espacios y fronteras en los reinos de Asturias-León y Pamplona», en Los espacios de poder en la España Medieval, pp. 315-339 o la obra de SÉNAC, P. (ed.), Frontières et espaces pyrénéens, Perpignan, Univ. de Perpignan, 1992.

7 No se debe olvidar la importancia de los intercambios económicos, a los que también los monarcas navarros prestaron una atención especial. No en vano los peajes de la zona ultraportana fueron una gran fuente de ingresos, además de servir para asignar en ellos ciertos honores a la aristocracia navarra.

8 Se puede hacer una selección de la amplia variedad de estudios dedicados a la frontera en la Península, en los que podemos localizar situaciones análogas a las de la aristocracia ultraportana, como el monográfico editado por la Casa de Velázquez (AYALA, C. de, et al.: Identidad y representación de la frontera), el seminario de la Universidad de Zaragoza sobre Las sociedades de frontera en la España Medieval o bien las actas del seminario sobre Espacios y organización social de la Universidad Complutense, o la publicación derivada del congreso sobre identidad, conflicto y representación de la frontera celebrado en Huéscar en septiembre de 2008 (RODRÍGUEZ DE LA PEÑA, M. A. (ed.): Hacedores de frontera. Estudios sobre el contexto social de la frontera Madrid, Fundación Universitaria San Pablo CEU, 2009), además de las sucesivas sesiones sobre Estudios de Frontera celebrados en Jaén y Alcalá La Real.

9 Véase para la zona labourdina, la obra de GARDELLES, J.: Les châteaux du Moyen Âge dans la France du Sud-Ouest, Ginebra, Droz, 1972 y en el caso de la Navarra peninsular, el magnífico estudio de MARTINENA, J. J.: Castillos reales de Navarra (siglos XIII-XVI), Pamplona, Gobierno de Navarra, 1994 o el artículo dedicado a una fortaleza ultraportana de HERREROS, S.: «El castillo de Rocabruna en Ultrapuertos», Príncipe de Viana, Anejo, n.ํ 14 (1992), pp. 381-386. 
En resumen, las elites que se movían en estos espacios generaron un sistema particular de relaciones, utilizando esta circunstancia para obtener beneficios, ya fueran tangibles o intangibles ${ }^{10}$. De este modo se desarrollaba un panorama en el que se mezclaba una cierta contestación ante la aplicación directa de la autoridad regia sobre el territorio y la asunción precisamente de esa autoridad que les ofrecía la posibilidad de aumentar su relevancia social -y económica- ${ }^{11}$. Por tanto, según lo que se ha explicado consideramos que las tierras navarras de Ultrapuertos representaban un laboratorio de análisis muy adecuado para determinar los mecanismos de resistencia de estos aristócratas fronterizos frente a la voluntad del monarca de imponer su dominio sobre el territorio y los hombres.

La cronología de este trabajo abarcará desde el comienzo de la presencia navarra en Ultrapuertos hasta el primer cuarto del siglo XIV con la muerte del último Capeto directo. Resulta sintomático que aún hoy los investigadores navarros no conozcan el momento concreto en el que los agentes del poder regio navarro se asentaron en este espacio ${ }^{12}$. En todo caso, su presencia se hizo evidente y rastreable a finales del reinado de Sancho $\mathrm{VI}$, al menos en lo que se refiere al control del territorio ${ }^{13}$, y a mediados del siglo XIII dentro del sistema de recaudación de la monarquía navarra ${ }^{14}$.

10 El componente humano de la frontera se encontraba también volcado en la obtención del beneficio de esta situación, tanto en el caso de comerciantes como de las elites rectoras - tanto municipales, como las de la parroquia de Urt en la zona labourdina, como de la aristocracia que nos ocupa en este trabajo- puesto que su situación como frontera también condiciona el flujo de recursos económicos. Véanse estudios sobre otros espacios fronterizos navarros en MUGUETA, I.: «Acciones bélicas en Navarra: la frontera de los malhechores", Príncipe de Viana, n. 219 (2000), pp. 49-77 o ZABALO, F. J.: «El acoso de guipuzcoanos y alaveses a los ganaderos navarros», Príncipe de Viana, n.․ 234, (2005) pp. 53-110.

11 De hecho, según se irá desgranando en líneas posteriores, se apunta una cierta resistencia frente al intervencionismo de los agentes reales navarros, pese a que la autoridad del monarca como dominador en el territorio no es en ningún caso puesta en tela de juicio. Esta situación es equivalente a la vivida en otras fronteras peninsulares, así lo afirma para territorios castellanos RODRÍGUEZ, Ana ( $L a$ consolidación territorial de la monarquía feudal castellana, Madrid, CSIC, 1994, p. 197).

12 Susana Herreros lo plantea como una estrategia de Sancho el Sabio para aumentar sus posesiones al otro lado de los Pirineos apoyándose en la coyuntura favorable derivada de la excomunión de Enrique II a raíz del asesinato del obispo Thomas Beckett [HERREROS, S.: Las tierras navarras de Ultrapuertos (siglos XII-XVI), Pamplona, Gobierno de Navarra, 1998, p. 63].

${ }^{13}$ En 1189 Martín Chipía se menciona como tenente de la tierra de Cisa, según DUBARAT, V.; DARANATZ, J. B.: Un procès entre l'évêché de Bayonne et le monastère de Roncesvaux avec une préface, des notes et des gravures, Bayona, Imp. Du Courrier, 1926, p. 111, mientras que en 1194, aparecía denominado como castellano de San Juan de Pie de Puerto (GARCÍA LARRAGUETA, S.: Archivo parroquial de San Cernin de Pamplona, Pamplona, Diputación de Navarra, 1976, doc. I). En teoría, también el rey de Navarra Sancho VI controlaba los castillos de San Juan de Pie de Puerto y Rocabruna desde época muy temprana, ya que habían sido entregados en dote a su hija Berengela en el momento de su matrimonio con Ricardo de Inglaterra (Como declara una carta de Inocencio III «...illustri regi Nauarre, ut pecuniam et castella Sancti Johannis de Pedeport et Rocca Bruna, que pater suus tibi cum filia sua concessit in dotem, sine aliqua difficultate restituat» transcrita por HAGENEDER, O.; HAIDACHER, A.; MURAUER, R.; et al.: Die Register Innocenz'Ill. 1. Band. 1. Pontifikatsjahr: Texte, Colonia, Verlag Hermann Böhlaus Nachf, 1964, Briefe I/229 bis 230; p. 324; doc. 230).

14 En las cuentas de 1266, publicadas en el volumen I de los AVRN y analizadas por GARCÍA ARANCÓN, M. ㄹ R., en sus artículos «La guerra de Gascuña de 1266», en El fuero de San Sebastián y su época, San Sebastián, Eusko Ikaskuntza, 1982, pp. 515-521 o «El servicio de armas en Navarra a 


\section{EL PROCESO DE CONSOLIDACIÓN DE LA AUTORIDAD REAL NAVARRA FRENTE A LOS GRUPOS ARISTOCRÁTICOS EN EL ESPACIO ULTRAPORTANO}

Este apartado se inicia esbozando las características generales de estas elites en varias pinceladas básicas, de cara a fijar convenientemente nuestro cuadro de estudio de las relaciones entre los reyes navarros y la aristocracia ultraportana. En primer lugar, existían muy pocos grupos familiares que se pudieran calificar como pujantes o de primer orden. Aún en este caso, sabemos que cobraron importancia precisamente a través de la integración en los mecanismos del poder navarros. Así, los Agramont o los Luxa llegaron a engrosar a mediados del siglo XIV la lista de los ricoshombres, el estamento de más prestigio dentro del reino de Navarra. Estos señores comenzaron controlado espacios no siempre extensos, pero sí estratégicamente situados, como ocurrió en el caso de los señores de Albret para la zona inglesa ${ }^{15}$. Hicieron de sus lealtades una punta de lanza para favorecer sus intereses territoriales, lo cual se observa perfectamente a lo largo de todo el proceso de asentamiento del poder navarro en Ultrapuertos desde finales del siglo XII hasta el siglo siguiente. De hecho sus actuaciones respecto a la monarquía navarra se podrían clasificar en torno a tres hitos fundamentales: el comienzo de la dominación navarra más allá de los Pirineos, los dos conflictos anglo-navarros y la guerra de la Navarrería.

\subsection{Toma de contacto con el mundo aquitano}

Durante los primeros años del proceso de asentamiento de la monarquía navarra en Ultrapuertos, que corresponderían a los inicios del reinado de Sancho VII, se podía observar una voluntad de control a través de la recopilación de las fidelidades no sólo ultraportanas sino en general del sudoeste francés. Más concretamente, se traslucía una necesidad de establecerse como organismo rector, para convertirse en una entidad mediadora y protectora a la que los poderes circundantes se dirigieran para solucionar sus conflictos privados. En esta línea, en 1196, poco después de que tengamos noticias concretas del establecimiento del poder real navarro al otro lado de los Pirineos, ya se solicitaba su arbitraje en un conflicto que oponía a dos entidades tan importantes en el sudoeste como eran el vizconde de Béarn y el vizconde de Soule, ambos a priori integrados en el ducado de Aquitania, cuya titularidad ostentaba el rey de Inglaterra ${ }^{16}$.

mediados del siglo XIII» en Temas de Historia Militar. I Congreso de Historia militar-Zaragoza, 1982, vol. I (Comunicaciones), Zaragoza, Academia Real Militar, 1983, pp. 123-131.

${ }_{15}$ Un fenómeno que explica en detalle el libro de MARQUETTE, J. B.: Les Albret: l'ascension d'un lignage gascon, Bordeaux, Ausonius, 2010.

${ }^{16}$ En la data del homenaje del vizconde de Tartas aparece detallado este conflicto "Quando Gasto Bearnensis venit ad curiam supranominati regis Navarre, apud Olit, pro causa quam habebat contra 
Por tanto, el primer objetivo del monarca navarro se centraba en convertirse en un actor más dentro del panorama aquitano, e intentaba atraer a su círculo a la mayor parte de los poderes circundantes, no sólo de sus tierras ultraportanas, sino también de los espacios colindantes con ellas. En este marco se pueden encuadrar, además de sus relaciones con la aristocracia autóctona, las que establecieron con otros monarcas. Así, en 1201 se firmó un pacto de alianza con Juan sin Tierra, que buscaba crear un frente común ante las aspiraciones de Alfonso VIII de Castilla ${ }^{17}$. Este último aspiraba, a través de la herencia de su esposa Leonor a la titularidad de los territorios aquitanos, disputándola al rey de Inglaterra ${ }^{18}$.

En la misma línea se situaba el establecimiento de un acuerdo con uno de los puertos principales del territorio labourdino, Bayona ${ }^{19}$, en el que el monarca navarro ofrecía su protección a cambio de una eventual ayuda contra sus enemigos, en concreto en previsión de una posible acción castellana ${ }^{20}$. De hecho, poco tiempo después, en 1205, Alfonso VIII franqueó la barrera pirenaica, apoyado por varios miembros de la aristocracia aquitana, como los Armagnac, el vizconde de Béarn o el señor de Tartas ${ }^{21}$. Desde San Sebastián se fletaron una serie de barcos que cercaron los puertos de Blaye, Bourg y comenzaron el asedio a Burdeos ${ }^{22}$. Sin embargo, el castellano detuvo su avance probablemente tras sopesar la dificultad que entrañaba la sumisión efectiva de los principales núcleos de población aquitanos, fieles al dominio inglés sobre todo a causa de los beneficios económicos que dicha relación les aportaba ${ }^{23}$.

Raymundum Guillelmi, vicecomitem de Sola» (Transcrito por BRUTAILS, J. A.: Documents des Archives de la Chambre des Comptes, París, Émile Bouillon, 1890, doc. I, pp. 1-3).

17 Véase RODRíGUEZ, A., op. cit., p. 90, citando los documentos de 1201 y 1202 transcritos por MARICHALAR, C.: Colección diplomática del rey don Sancho VIII el Fuerte de Navarra, Pamplona, Aramburu, 1934, n. $.25-26$, pp. 62-63. Para una panorámica general de las actuaciones del rey inglés Juan en Aquitania, ver VINCENT, N.: «Jean sans Terre et les Normands avant 1199: le comte de Mortain a la lumiere de ses chartes" en FLAMBARD, A. M., GAZEAU, V. (dirs.): 1204, la Normandie entre Plantagenêts et Capétiens, Caen, Publications du CRAHM, 2007, pp. 533-566.

${ }^{18} \mathrm{La}$ esposa del rey castellano era la hija homónima de Leonor, duquesa de Aquitania. Esta herencia aquitana será repetidamente reivindicada de nuevo por Alfonso $X$ que, tras otro episodio bélico reprimido de nuevo en Bordeaux por Enrique III, solucionó sus diferencias en 1254 a la vez que concertaba el matrimonio entre el príncipe Eduardo de Inglaterra con su hermana Leonor de Castilla, que aportaría como dote los pretendidos derechos sobre Gascuña (TNA, E 30/ 1108, y algunos documentos transcritos por RYMER, T.: Foedera, conventiones, literæ,... tomo I, Londres, HMSO, 1869, p. 310, 503).

${ }_{19}$ GOYHENECHE, F.: Bayonne et la région bayonnaise du XIle au XVe siècle, Bordeaux, Bassin, 1990 y recientemente BOUTOULLE, F., «Richard Cœur de Lion, Bayonne et le Labourd (1169-1199)", Annales du Midi, n. ${ }^{\circ} 275$ (2011), pp. 325-351.

20 Transcrito por BRUTAILS, J. A.: Documents des Archives de la Chambre des Comptes, doc. III, pp. 3-5.

${ }^{21}$ Veáse ALVIRA CABRER, M.; BURESI, P.: « Alphonse, par la grâce de Dieu, Roi de Castille et de Tolède, Seigneur de Gascogne: quelques remarques à propos des relations entre Castillans et Aquitains au début du XIII siècle ", en SENAC, P.(ed.): Aquitaine-Espagne (VIII -XIII siècle), Poitiers, Presses Universitaires, pp. 219-232, p. 221 y anexo I.

${ }^{22}$ En una carta de 1206 a favor de la catedral de Dax, Alfonso VIII se intituló «reinante en Gascuña». Este episodio de conquista ha sido estudiado en artículos como el de BOUTOULLE, F., «Un épisode méconnu de l'offensive d'Alphonse VIII de Castille en Gascogne", Cahiers du Vitrezais, n. ${ }^{\circ} 96$ (2004), pp. 33-40, el ya mencionado de ALVIRA, M., op. cit., y también HERREROS, S.: op. cit., 1998, pp. 73-76.

${ }^{23}$ RENOUARD, Y. (dir.): Bordeaux sous les rois d'Angleterre, Bordeaux, Fédération Historique du Sud-Ouest, 1965 pp. 24-27. 
Por tanto, para afianzar su poder en los valles pirenaicos ultraportanos, el rey de Navarra recibió en primer lugar el homenaje del vizconde de Tartas en $1196^{24}$, y el de Viviano, señor de Agramont, en $1203^{25}$, aunque ambos no olvidaron dejar patente su condición de vasallos del rey de Inglaterra, una carta de doble lealtad que se jugó constantemente a lo largo de todo el siglo XIII. Por su parte, Pedro Arnaldo de Luxa declaró su lealtad a Sancho VII en 1228, tras un enfrentamiento previo con el rey al haber fortificado su villa de Ostabat sin haber solicitado permi$\mathrm{so}^{26}$. Como vemos, desde fechas muy tempranas estos señores se acercaron al monarca navarro, aunque esto no les eximía de actuar en ocasiones de forma refractaria.

\subsection{La dinastía de champaña y los primeros enfrentamientos anglo-navarros}

Un segundo hito lo constituyeron los sucesivos enfrentamientos que opusieron los intereses navarros de la nueva dinastía de Champaña - focalizados dentro de la órbita francesa-, contra los sucesivos intentos del rey inglés como duque aquitano de restablecer su control en las áreas fronterizas con Ultrapuertos, que escapaban paulatinamente a su dominio. Este proceso se aceleró cuando, hacia 1242 , Enrique III de Inglaterra programó un ataque contra ciertas tierras que le había arrebatado anteriormente el monarca francés, espoleado por lo más granado de la aristocracia aquitana ${ }^{27}$.

Sin embargo, fue derrotado en Saintes ${ }^{28}$ y en Taillebourg, y se produjo una primera oleada de homenajes ultraportanos al nuevo rey de Navarra. Éste provenía nada menos que del círculo más cercano al rey de Francia, y ostentaba el título de conde palatino, de modo que si el poder inglés menguaba en la zona, resultaba una alianza segura. El primero de ellos fue el Pedro Arnaldo, señor de Sault de Hasparren - una parroquia localizada en tierras labourdinas-, que en 1238 prestó homenaje a Teobaldo I por una pieza de tierra que le había donado éste último en Orzate ${ }^{29}$. Por tanto, este homenaje es anterior al conflicto inglés, pero resulta sintomático de la situación que se producirá después. Personajes relevan-

24 Veáse nota 16.

25 BRUTAILS, J. A.: op. cit., doc. II, p. 3.

26 «Ego, don P. Arnalt de Luxa feci aveniença con vos don Sancho, por la gracia de Dios rei de Navarra, quando me tornastes esta villa d'Ostavals, atal aviniença fiz con vos que io non faga fortaleza ninguna en Ostavals (...) et demas que aiades en Ostavals todo aquel sennorio que nunque $i$ oviestes ni avesdes ni devedes aver. Demas, io deviengo vuestro vassaillo» (ibídem, doc. IV, p. 5.).

27 En concreto, los nobles gascones eran Gastón VII de Béarn, los condes de Bigorra y Armagnac y el vizconde de Tartas, que se reunieron con las villas inglesas de Burdeos, Bayona, Dax, La Réole y Saint Emilion en Pons el 24 de mayo de 1242 para plantear su oferta al senescal inglés. (HIGOUNET, Charles: Histoire de Bordeaux, tomo III, p. 94).

${ }_{28}$ Un enfrentamiento referenciado incluso en las reclamaciones derivadas del conflito anglo-navarro de 1244 «Et aço fu quant lo rey d’Anglaterra fu a Sayntes» AGN, Comptos, caj. 5, n.ํ 39, IV, fol. 4r.

29 MARTíN, M.: op. cit., doc. 84, p. 119 «propter illam donacionem feci homagium ligium». 
tes tanto dentro del marco ultraportano como en general de las tierras de sudoeste francés, como Fortaner de Lascun - por quien se presentó garante el propio vizconde de Béarn - o Roger de Comminges, el hijo del conde de Pallars, prestaron homenaje ligio a Teobaldo I en $1244^{30}$, dentro del contexto de la derrota inglesa sufrida a manos francesas y del comienzo de las hostilidades directas entre el rey inglés y el navarro por las tierras de Mixa y Ostabares en Ultrapuertos ${ }^{31}$.

Del mismo modo, Raimundo Guillermo IV, vizconde de Soule, se convirtió en vasallo de Teobaldo I en 1244 siguiendo la misma tónica que los personajes anteriores, aunque el juego de alianzas de su familia oscilará también entre las lealtades navarra e inglesa ${ }^{32}$. En esencia, sus tierras se encontraban en territorio inglés, además de encontrarse en la órbita de los vasallos del vizconde de Béarn. De ese modo, el homenaje al rey de Navarra no eximió a su descendiente, Raimundo Guillermo V, de ser convocado a la ost de Saint-Sever por Enrique III de Inglaterra para prestar ayuda militar en su contienda contra el rey de Francia ${ }^{33}$. Posteriormente, sin embargo, su presencia en el seno de una revuelta de grandes feudatarios gascones encabezada precisamente por Gastón VII de Béarn, provocó que el castillo de Mauleon fuera asediado y rendido a los ingleses. Tras una serie de negociaciones y el pago de ciertas multas, uno de los herederos del señorío, Auger de Mauleón, tuvo que intercambiar el vizcondado de Soule en 1261 por las tierras del Marensin, Laharie, Saubusse, Saas y Angoumé, aunque continuó al servicio de los reyes de Navarra, obteniendo a cambio diferentes ventajas, como ciertas rentas en Estella en $1280^{34}$. Mientras tanto, las tierras souletinas, que anteriormente habían estado en manos de aliados de la monarquía navarra, habían pasado a manos de capitanes-castellanos ingleses a finales del siglo XIII, amenazando a partir de ese momento directamente la frontera Este de los territorios ultraportanos ${ }^{35}$, lo cual demuestra que no siempre las estrategias de acercamiento a los poderes circundantes aportaban los resultados deseados.

${ }^{30}$ AGN, Cart. 3, p. 167; Comptos, caj. 2, n.ำ 14, III; caj. 2, n.ำ 43, V; transcritos por MARTíN, M.: op. cit., doc. $97,100,104$.

${ }_{31}$ Un conflicto que ha sido ampliamente tratado en el excelente texto de VINCENT, N.: «A Forgotten War: England and Navarre 1243-4» en Thirteenth Century England XI Proceedings of the Gregynog Conference, 2005, Woodbridge, Boydell and Brewer, 2007, pp. 109-46.

${ }^{32}$ Lo que se observa en el propio texto de su homenaje en el que se afirma que«... deue fer seruicio a seinnor, nompnadament contra Bearn, contra Agramont et contra todos los otros hommes del mundo, saluo contra aqueilla tierra que el rei d'Anglaterra tiene estament en so mano et en so dominio, demas prometo que si el rei d'Anglaterra o el senescal de Gascoynna o qui quiere que ueniesse sobre uostra tierra uos auide a deffenderla como leal vasaillo es tenido a seinnor, et non uenga contra uos por nenguno ni por nenguna» (AGN, Comptos, caj. 2, n.․ 14, III).

${ }_{33}$ Debía acudir con 5 caballeros, según MICHEL, F.: op. cit., p. 23, n.ำ159, del 25 mayo 1242: «(...) ita sufficienter parati equis et armis (...) Vicecomes de Syule, se V. ${ }^{\circ}$...)».

${ }^{34}$ AVRN, Tomo II/ I, p. 69, en concreto según se detalla en 1286, sobre la pecha de Murugarren, Azanza, Izurzu, Muniain, Ayzquena, Arizala, Cirauqui, Urbe, Vidaurre, Lezaun, Herendazu (AVRN, Tomo II/ II, p. 730).

${ }_{35}$ En TNA, E 101/ 699/ 28 aparece un registro de las reparaciones y los suministros para los castillos gascones. 
Después de una fuerte lucha contra las tropas navarras en las tierras de Mixa y Ostabares, cuya titularidad ostentaba, el vizconde de Tartas también se unió en 1247 la lealtad navarra ${ }^{36}$. Dentro del homenaje incluyó a sus hijos Pedro de Dax y Ramón Roberto, que posteriormente renovaron su homenaje a Teobaldo II ${ }^{37}$. Tanto el vizconde de Soule como el señor de Luxa se presentaron como garantes de su lealtad ${ }^{38}$. De hecho, el vástago de este último, Brasc García III, prestó a su vez juramento de lealtad al monarca navarro en 1258 por su castillo y sus tierras patrimoniales ${ }^{39}$. En cualquier caso, en el homenaje del vizconde de Tartas se exigieron muchas garantías, quizá por la importancia que revestían los territorios de Mixa y Ostabares para el monarca navarro, ya que se encontraban en pleno corazón del territorio ultraportano ${ }^{40}$.

Sin embargo, esta familia no abandonó el vasallaje al rey inglés ${ }^{41}$, al que estaba vinculada por otros territorios fuera de Ultrapuertos, por ejemplo las tierras de Auribat ${ }^{42}$ o varias parroquias en la diócesis de Dax, como las de Santa Cruz, San Aignan y Lesgor, en las que el propio monarca inglés le otorgó la jurisdicción ${ }^{43}$. Así mismo, también apoyó a Eduardo de Inglaterra con sus fortalezas de Gamard y Clairmont en su enfrentamiento contra los intereses franceses ${ }^{44}$. De hecho, como último detalle se puede mencionar que el vizconde de Tartas fue uno de los pocos representantes de la aristocracia aquitana que aportó su ayuda a Simón de Montfort para que pudiera ejercer sus funciones de delegado del monarca inglés en $1253^{45}$, y siguió contando con la protección y las rentas que le ofrecía el monarca de Inglaterra, en concreto de 600 libras morlanes en $1254^{46}$. Como se puede observar, este grupo manejaba ambas lealtades con soltura para obtener beneficios tangibles, honores y cargos $^{47}$.

\footnotetext{
${ }^{36}$ Ibídem, doc. 119, p. 153.

${ }_{37}$ «E Pedro Dax e Remon Robert, mios fillos, han jurado en aqueilla misma forma que yo jure» (ibidem, p. 154).

38 Ibídem, doc. 120 y 121, pp. 156-157.

39 GARCía ARANCÓN, M. ${ }^{\text {a }}$ R.: Archivo General de Navarra (1253-1270), tomo II, Comptos y Cartularios Reales, Donostia, Eusko Ikaskutza, 1996, p. 41, n.ㅇ 39, transcrito del AGN, Comptos, caj. 2 , n. ${ }^{\circ} 59$, II, fol. $1 \mathrm{r}-1 \mathrm{v}$.

40 También el propio vizconde de Tartas comprometió sus peajes de Garriz y Mauburguet para garantizar su lealtad. Ibídem, doc. 122, p. 159-160.

${ }^{41}$ MICHEL, F.: op. cit., doc. 159, p. 24.

42 Ibídem, p. 248, doc. 1930.

43 BÉMONT, Ch., op. cit., Tomo Il, p. 491, doc. 1589.

44 Ibídem, doc. 1359, p. 422: «Noveritis quod propter gratia servicia que dilectus et fidelis noster Raymundus Roberti, vicecomes Tartacensis, nobis impedit, damus et concedimus pro nobis et heredibus nostris eidem vicecomiti et heredibus suis altam justiciam in castro suo de Gamardo et pertinenciis suis, quantum feodum vel retrofeodum dicti castri protenditur" y MICHEL, F.: Rôles Gascons, tomo I, p. 333 , doc. 2539.

${ }_{45}$ BÉMONT, Ch.: Simón de Montfort, op. cit., pp. 48 y 50, citando la Chronica de Mateo Paris, tomo V, p. 334; MADDICOTT, J. R.: Simon de Montfort, Cambridge, Cambridge Univ. Press, 1994.

${ }^{46}$ MICHEL, F.: op. cit., tomo I, p. 281, doc. 2187; p. 390 doc. 3041.

47 HERREROS, S.: op. cit., 1998, pp. 97-98.
} 
Por tanto, durante los primeros años del reinado de Teobaldo I se produjo un posicionamiento de aristocracia ultraportan en un frente más cercano a los intereses navarros, e incluso es posible observar una cierta redefinición de las fronteras. Por ejemplo los habitantes de la parroquia labourdina de Urt, situada en la confluencia del Joyeuse con el Adour se habían colocado bajo la protección de Teobaldo I en 1243 a cambio de un francaje, una acción provocada también por intereses comerciales, ya que representaban una interesante salida navegable hacia el mar para los territorios ultraportanos ${ }^{48}$. Del mismo modo, tanto el monarca inglés como el navarro reivindicaban la titularidad de la parroquia fronteriza de Ainhoa ${ }^{49}$, un punto geoestratégico fundamental, ya que daba acceso a los pasos pirenaicos de Maya hacia el valle navarro del Baztán ${ }^{50}$.

Existe un segundo punto de inflexión en el proceso de orientación de las lealtades hacia los intereses navarros. En efecto, en 1259, el llamado Tratado de París establecido entre Luis IX de Francia y Enrique III de Inglaterra estipulaba el homenaje de éste último, en su calidad de duque de Aquitania, al francés. A cambio, se le restituirían varios territorios ocupados por los franceses, como el Agenais, el Quercy y la Saintonge ${ }^{51}$. De esta forma, y como puso en boca del monarca el propio Jean de Joinville, contemporáneo de Luis IX, «obtuvo un vasallo que antes no tenía " 52 y adquirió nuevas formas de controlar el territorio gascón, siguiendo así con una política de asentamiento de su poder en el sudoeste francés. El homenaje feudal que prestó el soberano inglés por el ducado de Aquitania colocaba a Francia en una situación de superioridad que fue constantemente utilizada y recordada por los monarcas posteriores a San Luis.

A raíz de este homenaje se abre una profunda brecha jurisdiccional que debilitó notablemente la autoridad inglesa en toda la zona aquitana. Suponía una vía de contestación para la aristocracia autóctona, ya que les permitía superar la jurisdicción inglesa, representada por el senescal de Gascuña y el condestable de Burdeos, apelando directamente a la Corte francesa como instancia superior, y

48 Véase el texto transcrito por MARTÍN, M.: Colección Diplomática de los reyes de Navarra de la dinastía de Champaña. Teobaldo I (1234-1253), San Sebastián, Eusko Ikaskuntza, 1987, p. 125, n.ㅇ 91.

${ }^{49}$ Así lo afirma un documento inglés en 1305 « que par la ou la paroche de Aigno, que est en la marche de Gascoigne de Navarre, la quele paroche des genz de Navarre de cele marche disent que est de leur seigneurie et les genz nostre seigneur le rei de de La Burde et de cele marche en Gascoign disent que la dicte parochie est de la seigneurie nostre seigneur le rex 》 (TNA, SC 8/338/ E 1244). Otro documento reivindicando su pertenencia al rey-duque se encuentra transcrito por BÉMONT, Ch.: Rôles gascons, vol. II, 1273-1290, Col. documents inédits sur l'histoire de France, Paris, Imprimerie nationale, 1900 doc. 1195 , p. 374 .

50 También denominado como puerto de Dantxarinea.

51 Sin embargo, al renovar su hijo Eduardo I el homenaje en 1273, aún no habían sido devueltos. PRESTWICH, Michael: Plantagenêt England: 1225-1360, Oxford, Oxford Univ. Press, p. 298. Para el estudio pormenorizado de este tratado, se puede acudir a la obra de GAVRILOVITCH, M.: Étude sur le Traité de Paris de 1259 entre Louis IX, roi de France, et Henri III, roi d'Angleterre, col. Bibliotèque de l'École d'Hautes Études n. 125, París, Émile Bouillon, 1899.

52 «/l m'est moult grant honneur en la paix que je foiz au roy d'Angleterre, pour ce que il est mon home, ce que il n'estoit pas devant» JOINVILLE, Jean de: Vie de Saint Louis, Paris, Classiques Garnier, p. 32. 
por tanto obteniendo una impunidad relativa mientras esta apelación se resolvía a través de los cauces adecuados, ya que dejaban de estar bajo la jurisdicción inglesa hasta que se resolviera el conflicto ${ }^{53}$. Por ejemplo se podría citar una reclamación de Amaneo, señor de Noaillan —un territorio situado en el Bordelais- que elevó al parlamento francés por la actuación del monarca inglés en sus territorios. Como era de esperar, los franceses otorgaron la razón al señor de Noaillan, fallando en contra del procurador inglés y ordenándole el pago de 1000 libras de multa, a pesar de que durante el enfrentamiento Amaneo había retenido una serie de rehenes en su propia casa, que los agentes franceses le obligaron a liberar ${ }^{54}$.

En resumen, a mediados del siglo XIII y a raíz del Tratado de París, la autoridad inglesa sobre estos aristócratas aquitanos se iba minando cada vez más, de modo que buscarán en el monarca navarro un nuevo aliado. Por otro lado, el monarca inglés quedaba sometido al menos nominalmente por un homenaje a las directrices francesas, por lo que su poder jurisdiccional se veía también comprometido, al quedar el rey de Francia como instancia superior.

La toma de posición a favor de los navarros por parte de las grandes familias ultrapirenaicas se revela en las vísperas del conflicto que opondría a Teobaldo II y Enrique III en 1266. El rey navarro se encontraba perfectamente alineado con los intereses franceses, ya que estaba casado con una hija de San Luis y había sido educado en la Corte ${ }^{55}$, así que representaba un elemento fundamental dentro de la estrategia capeta de hostigamiento a los ingleses en Aquitania. De este modo, los aristócratas del sudoeste se posicionaron en las filas navarras ante la debilidad inglesa derivada en su mayor parte del homenaje prestado al rey francés. A continuación, se van a citar algunos ejemplos concretos a través de los cuales es posible observar cómo van a bascular sus lealtades -o como combinan ambos homenajes, el navarro y el inglés-.

En primer lugar se puede mencionar a Bernardo, conde de Comminges, que había formado parte de las tropas inglesas en el conflicto anglo-francés de $1242^{56}$, sostuvo la causa de Teobaldo II en 1266 contra estos mismos intereses ingleses,

${ }^{53}$ Las quejas a este respecto no paraban de emanar de la cancillería inglesa, por ejemplo en 1272 (RYMER, Thomas: Foedera...tomo I, p. 82) y también intentó ser regulado en el Parlamento de Paris de 1286 (BOUTARIC, M. E.: Actes du Parlement de Paris. Tome premier 1254-1299, Paris, ed. Plon, 1863, doc. 2363 y 2363 A, p. 240$)$.

54 Un caso citado en el Parlamento de 1322. Del mismo modo en 1320 también se localiza una sentencia que suprimía la anterior del senescal de Gascuña cotra García Arnaldo, señor de Navailles, caballero, por haber cabalgado a través los prebostazgos de Saint Sever y Dax «con las banderas levantadas y un gran séquito de hombres armados a pie y a caballo». Ver BOUTARIC, M. E.: Actes du Parlement de Paris (1254-1328), tomo II..., p. 358, 469; n.․ 6380, 6889 (1320-1322).

55 Del mismo modo que su padre, hijo póstumo, se había educado en la Corte de Felipe Augusto. Existen varias obras sobre este monarca que hacen hincapié sobre sus relaciones francesas, sobre todo de GARCÍA ARANCÓN, M. R.: Teobaldo II de Navarra (1253-1270). Gobierno, monarquía y recursos financieros, Pamplona, Gobierno de Navarra, 1985, o la propia tesis de HERREROS, Susana (Las tierras navarras de Ultrapuertos (siglos XII-XVI), Pamplona, Gobierno de Navarra, 1998).

56 «Sciatis quod tenemur Bernardo, comiti Convennarum, in centum et quindecim libris sexdecim solidis et octo denariis sterlingorum de arreragiis vadiorum suorum de tempore quo fuit nobiscum in 
según aparece en la contabilidad real de ese año. Así mismo, en estas cuentas es posible rastrear también la presencia en las filas navarras nada menos que de Amanieu de Albret ${ }^{57}$, cuya familia había sido -y continuó siendo- uno de los apoyos principales del monarca inglés en las tierras continentales ${ }^{58}$.

De la misma manera, en las filas navarras se asociaron señores de procedencia tan dispar como Bernardo, conde de Astarac ${ }^{59}$ que un año antes ya había prestado homenaje a Teobaldo II mediando 1.500 sueldos morlanes anuales ${ }^{60}$; Ramón Guillem de Caupenne, cuyas tierras patrimoniales se localizaban en la zona de Mugron, entre Dax y Saint-Sever y procedente de otro grupo familiar muy asociado al poder inglés ${ }^{61}$; Fortaner, señor de Lavedan, que se encontraba dentro de la órbita del vizconde de Béarn ${ }^{62}$, e incluso uno de los hijos menores de Simon de Montfort, Ricardo, que tras la muerte de su progenitor y la cesión del condado de Bigorra por parte de su madre a Teobaldo ${ }{ }^{63}$ entró al servicio de este último contra los ingleses en $1266^{64}$.

Otro caso de cambio de lealtades a raíz de los conflictos anglo-navarros lo constituyeron los señores de Agramont. Si bien estos señores habían prestado homenaje al monarca navarro a comienzos del siglo XIII, a lo largo de toda esa centuria oscilaron entre las ventajas que ofrecía el vasallaje inglés y la cercanía que ofrecían las tierras navarras de Ultrapuertos, además de los cargos que se le

servicio nostro in Wasconia» transcrito en MICHEL, F.: Rôles Gascons 1242-1254, vol. I, Paris, Impr. Nationale, 1885, p. 539, doc. 4287.

57 En el año 1266, ver AVRN, Tomo I, p. 238, 289, en el que se registran un préstamo de 150 libras y el pago de unos gastos - seguramente militares- de 300 libras generados durante ese año.

${ }_{58}$ Hasta el punto de acompañar a Eduardo I en sus campañas contra los galeses (RYMER, T. : op. cit., tomo II, p. 206)

${ }_{59}$ Que sin embargo, había sido convocado a la ost de Enrique III de Inglaterra en 1254, al igual que el señor de Comminges, veáse MICHEL, F.: op. cit., doc. 3615-6, p. 444.

60 Salvaguardando su fidelidad al conde de Toulouse, a la sazón Alfonso de Poitiers, hermano del rey de Francia (homenaje en AGN, Comptos, caj.2, n. 102).

61 Elías, señor de Caupena, fue senescal de Perigord, Limousin y Quercy en 1289 y su hermano, Pedro Arnaldo de Caupena le sucedió en este mismo cargo hacia 1305 (BÉMONT, Ch.: op. cit., introducción, p. LXXXIV y LXXXV; y J. P. TRABUT-CUSSAC: L'administration anglaise en Gascogne sous Henry IIl et Edouard ler de 1254 à 1307, Ginebra, Droz, 1972, p. 183).

${ }^{62}$ Y que en 1266 ejerció incluso como tenente en Bigorra para el rey de Navarra (ANF, J 198, n.․ 107, citado por GARCÍA ARANCÓN, M. R.: «La guerra de Gascuña de 1266», op. cit.).

63 La herencia del condado de Bigorra generó una situación conflictiva en estas mismas fechas que implicó también a la mayor parte de los poderes que actuaban en la zona aquitana: el entorno del vizconde de Béarn, la iglesia del Puy, la familia de Monfort y naturalmente los monarcas inglés, francés y navarro (Un proceso que ha generado una abundante bibliografía, como MERLET, L.: «Procès pour la possession du comté de Bigorre", Bibliothèque de l'Ecole des Chartes, n. III (1857) pp. 305-324; DARBOIS, H.,Histoire des ducs et des comtes de Champagne, vol. IV, París, 1865, pp. 375-382. BEMONT, Ch.: Simon de Montfort, comte de Leicester, Ginebra, Droz, 1976, pp. 77-81; BALENCIE, G.: « Le procès de Bigorre ", Revue des Hautes Pyrénées, n.ำ 3 (1908), pp. 44-48, 122-129, 276-282, 416-424; n. 4 (1909), pp. 40-49, 169-180, $321-333$ y n. 5 (1910), pp. 5-15; POWICKE, F. M.: King Henry III and Lord Edward: the community of the realm in the thirteenth century, vol. I, Oxford, The Clarendon Press, 1950, pp. 220-227 o HIGOUNET, Ch.: Le comté de Comminges de ses origines à son annexion a la couronne, vol. I, Toulouse-Paris, Privat, 1949, pp. 121 y ss.).

${ }^{64}$ Al que dedicó un artículo GARCÍA ARANCÓN, M. R.: «Ricardo de Montfort al servicio de Teobaldo II de Navarra», Príncipe de Viana, n.ำ 160/161 (1980), pp. 411-417. 
otorgaron, como veremos en líneas posteriores. Hacia 1242, cuando Enrique III programó su ataque contra las tierras que le había arrebatado el monarca francés, se aseguró de mantener la lealtad de Guillermo Arnaldo de Agramont, al que concedió 500 libras morlanes ${ }^{65}$ y un feudo anual de 20 libras sobre las rentas de la villa de Bayona ${ }^{66}$. El monarca inglés, al solicitar su apoyo, era perfectamente consciente de su situación como vasallo de Navarra y de su posible vuelta a la lealtad anterior, de hecho, podría ser la razón de que le ofreciera constantes ventajas ${ }^{67}$. Además, contaba con el señor de Agramont para configurar sus tropas, como así lo atestiguó un llamamiento a la hueste inglesa de 1253 en el que se le exigía acudir con 30 ballesteros y cien soldados a pie. De hecho, esta cifra representaba además su importancia dentro del grupo aristocrático del sudoeste, puesto que si bien era un noble de segundo rango, su poder de convocatoria resultaba notablemente alto ${ }^{68}$. También reprodujo el homenaje por sus tierras en 1255 y 1263, de modo que aún en esas fechas se mantenía dentro del círculo de aliados ingleses ${ }^{69}$.

Poco después tuvo lugar el punto de inflexión dentro del cuadro de lealtades de los señores de Agramont, quizá generado por los problemas anteriores con los representantes reales ingleses ${ }^{70}$ o por el estricto control al que eran sometidos, ya que contaban con un representante real en el propio castillo de Agramont ${ }^{71}$. En cualquier caso, Arnaldo Guillermo de Agramont y sus hijos Arnaldo Guillermo y

65 MICHEL, F.: op. cit., tomo I, doc. 431, p. 58: "Sciatis quod tenemus Willielmo Ernaldo de Egremundo in quinquaginta libris morelensibus reddendis ei quando thesaurario noster venerit de Anglia».

66 «Scias quod concessimus Willelmo Ernaldi de Egremund annuum feodum XX librarum Morelensium singulis annis percipiendum ad Pascha, per manum tuam, quandiu fuerit ad fidem et servicium nostrum. " Transcrito en Ibídem, doc. 433, p. 59, y CHAMPOLLION-FIGEAC, M.: Lettres de rois, reines et autres personnages des cours de France et d'Angleterre depuis Louis VII jusqu'à Henri IV, vol. I, París, Impr. Nationale, 1839, doc. L, pp. 61-62.

67 ibídem, doc. 1640, p. 212 «qui ad nos reversum est de rege Navarre, quod idem rex intendit tueri et manutenere Arnaldum Willielmi de Egremunde contra nos, dicens castrum Acris Montis esse de feodo suo. Nos vero, licet sciamus quod castrum illud sit de dominico et feodo, non volumus quod guerrata eidem regi moveatis castrum predictum obsidendo(...)».

68 MICHEL, F.: op. cit., tomo I, doc. 3558, p. 438, «Mandatum est Ernaldo Guillelmi de Acro Monte quod mittat regi triginta ballistarios equitos et centum pedites». Así aparecía dentro de una larga lista de personalidades convocadas a la ost, incluso eclesiasticas, como el obispo de Limoges que debía mandar 20 ballesteros a caballo.

69 BÉMONT, Ch.: Recueil d'actes relatifs à l'administration des rois d'Angleterre en Guyenne au 13e siècle (Recogniciones feodorum in Aquitania), Paris, Impt. Royale, 1914, doc. 479, p. 208; y en 1263: "Conegude cause sie que nos, n’A. W. de Gramont e A. W. e Auger, nostres filhs, auem jurat sober sentz al nostre noble senhor N'Adoart, filh deu roi d'Anglaterre, e al noble senhor En Gasto de Bearn que lieus bassages e fideus e seruidors los serram...» (ibídem, doc. 476, p. 205). En este segundo homenaje además reiteraban su fidelidad a los vizcondes de Béarn.

70 En 1248, Arnaldo Guillermo se presentó ante una corte judicial que había convocado en Burdeos Simon de Montfort, que inmediatamente decretó su arresto y lo hizo trasladar a la prisión de La Reôle, donde permaneció hasta 1252, a pesar de la intercesión de varios nobles y la del propio monarca inglés, que ordenó su liberación en 1250 (BALASQUE, J.: Études historiques sur la ville de Bayonne, vol. II, Bayona, Impr. Lasserre, 1869, pág. 159).

71 Así lo atestiguaba un documento inglés de 1255 (MICHEL, F.: op. cit., tomo I/I, doc. 4675, p. 55) «Willelmum Arnaldi de Tardez, constabularium nostrum de Acromonte, sibi deberi pro pilotis et fundis ingeniorum factia apud castrum predictum eisdem solvat». 
Oger de Sorhaburu en Mixa juraron fidelidad al rey navarro, para continuar en ella durante la segunda mitad del siglo XIII, sobre todo durante el enfrentamiento anglo-navarro de $1266^{72}$.

Por otro lado, en las cuentas navarras derivadas de los enfrentamientos de 1266 -y posteriores - se puede constatar de nuevo la participación como mesnaderos de la mayor parte de pequeña y mediana aristocracia ultraportana, centrada en obtener beneficios tangibles por sus lealtades.

En resumen, la aristocracia ultraportana y, por extensión, la de las zonas fronterizas, reconoció a los nuevos reyes champañeses de Navarra como claros aliados de los monarcas capetos. Esto se sumaba a la pérdida de autoridad del rey inglés en la zona, derivada del homenaje realizado al rey francés por estos territorios, en calidad de duque de Aquitania. Por tanto, las elites ultraportanas y de los espacios labourdinos circundantes tomaron partido por el monarca navarro -sobre todo en las escaramuzas de 1266 - ofreciendo su lealtad, su homenaje y su servicio militar en las filas del ejército navarro.

\subsection{La casa de Francia en el trono navarro}

Las actuaciones de esta elite seguirían la misma tónica hasta el siguiente hito que se ha comentado, momento en el cual se les ofreció una oportunidad inigualable para cobrar mayor importancia dentro de los cuadros de gestión y decisión del reino de Navarra. Esta se presentó a raíz del cambio de dinastía producido a finales del siglo XIII tras la muerte de Enrique I, rey de Navarra y conde de Champaña, al recaer la corona navarra en su hija Juana, casada con el vástago y sucesor del rey de Francia, Felipe. En ese momento se produjo un enfrentamiento armado entre un sector de la aristocracia «tradicional» navarra, poco inclinada a aceptar el control capeto que restringiría sus privilegios, y los representantes enviados por el monarca Felipe III el Atrevido para asegurar a su vástago en el trono ${ }^{73}$. En las filas del ejército francés militaban grandes feudatarios de la zona aquitana, como el conde de Foix, el de Armagnac, el de Perigord, el señor de Sault de Navailles o Jourdain de l'Isle, cuyos intereses se encontraban bastante alejados de tierras navarras ${ }^{74}$, sin olvidar al propio Gastón de Béarn, al que en un

72 GARCíA ARANCÓN, M. R.: AGN, it., p. 79, n. 67, transcrito de AGN, Comptos, caj. 4, n.ำ 24: Arnaldo Guillermo de Agramont se declaraba «ombre lige» por el castillo de Agramont, «et todos queylllos que seran seynores del castiello d'Agramont» y además «rogue et pregue a mios fillos, Arnalt Guillem et Oger de Sarburu» que juraron también.

73 MARTÍN DUQUE, A. J.: «El señorío episcopal de Pamplona hasta 1276», Príncipe de Viana, n. 227 (2002), p. 806; ídem y RAMÍREZ, E.: «El reino de Navarra (1217-1350)» en Historia de España, tomo XIII/II, p. 53-55 y el estudio preliminar de MICHEL, F., Histoire de la guerre de Navarre en 1276 et 1277 par Guillaume Anelier de Toulouse, París, Impr. Impériale, 1857.

${ }_{74}$ Ibídem, XCVI, f 129v: "Amenego las ostz ab mantas belas gens./Lay y fu don Gaston, qu'es de gerra sabens, / e.I valent com de Fuis, de guerregar ardens,/e.I comte d'Armaynnac, gayllart ez avinens,/e.I com de Pereguerc (Perigord), savis e conoyssens,le.n lorda de Ylla e sos filtz yssamens, / e.n Cicart (Si- 
momento dado el poema sobre el luctuoso evento redactado por Guilhem Anelier de Toulouse denominó como señor de los gascones, por su preeminencia sobre el resto de la aristocracia ultrapirenaica ${ }^{75}$.

La llegada de la casa de Francia al trono navarro no cambió el proceso de atracción de las grandes familias del sudoeste francés, que ya se había iniciado en la etapa anterior, a raíz sobre todo del Tratado de París. Sin embargo, la perspectiva resultaba diametralmente distinta. Los monarcas navarros anteriores buscaban en estos apoyos la ratificación de su dominio más allá de los Pirineos, ya que estas alianzas hacían patente y visible su presencia como un poder relevante dentro de la escena aquitana. Por otro lado, también integraban estas alianzas en un marco defensivo frente a la amenaza que representaban las aspiraciones de otros reinos peninsulares, como por ejemplo Castilla, que también se había interesado por sus derechos al territorio detentado por el rey-duque ${ }^{76}$. Por el contrario, a partir de 1274 el reino de Navarra, - sin perder su definición como tal- pasó a estar controlado por la Casa real francesa, y por tanto, se identificó plenamente con la política de hostigamiento directo a los intereses ingleses ${ }^{77}$. En resumen, ya no se trataba tanto de configurarse como un poder activo en la escena aquitana, sino de atraer hacia la órbita francesa a la aristocracia de lealtad inglesa, para disminuir progresivamente el control del monarca anglosajón sobre el ducado de Aquitania ${ }^{78}$.

En consecuencia, los grandes señores aquitanos se alinearon en las filas navarras en función de sus intereses privados, generalmente relacionados con obtener un mayor control territorial frente a los intentos de los ingleses de mantener una autoridad pujante sobre este territorio. Como última muestra, se puede presentar la actividad de Gastón VII de Béarn, uno de los personajes más relevantes dentro de la escena política del sudoeste francés en el siglo XIII. Estuvo ligado a los intereses ingleses ${ }^{79}$, participando incluso en las campañas galesas ${ }^{80}$, aunque también se opuso activamente a la gestión en tierras continentales de Simón de Montfort, por lo

card) de Montaut, Jordan de Rabastens,/e.I seynne de Calmont(Caumont), e.I seynne de Berens(Berenx)/ e fo y Ramón Roger, de Lanays en Climens,le.I viscoms d'Avilar (Auvilliers), e.l seynne de Tonoens (Tonneins),/Bertrand de Cardeyllac y fo apertamens,/ e.I seynne de Navaylla».

75 Llevaron la cocina del «señor de los gascones» al lugar donde más golpeaba el trabuquete de los burgos según Ibídem, p. 272, LXXXVIII, f. 114r.

76 Derechos arbolados anteriormente por Alfonso VIII, como se ha comentado en la nota 18.

77 Un proceso que, como hemos visto en líneas anteriores, ya se había iniciado durante el reinado de los condes de Champaña, como lo testimoniaban los enfrentamientos anglo-navarros de 1247 y de 1266.

78 Esta voluntad constante ya se observa desde el Tratado de París de 1259 y que se analiza en obras clásicas como la de GAVRILOVITCH, M.: op. cit., o los trabajos de FOWLER, K. (ed.):, The Hundred Years War: England and France at War c.1300-c.1450, ed. Macmillan, Londres, 1971; FAVIER, J.: Philippe le Bel, Paris, Fayard, 1978, o M. VALE: The Origins Of The Hundred Years War: The Angevin Legacy 1250-1340, Oxford, Oxford University Press, 1996, o ídem: «The War in Aquitaine» en CURRY, A., et al. (ed.): Arms, Armies and Fortifications in the Hundred Years War, Londres, The Boydell Press, 1994, pp. 69-82.

79 Comprometido por su homenaje, al igual que el de su progenitor a Enrique III en 1228 (Transcrito parcialmente por MARCA, P. de: Histoire de Béarn, vol II, Pau, Ribaut et Lafon, 1901, p. 315).

80 En 1282, según lo transcribe RYMER, T.: op. cit, tomo II, p. 206. 
que fue convocado para explicarse ante la Corte en Londres ${ }^{81}$. Sin embargo, esto no le impidió avalar a varios caballeros en sus homenajes al rey de Navarra ${ }^{82}$. Más tarde, en 1273, se volvería a levantar contra los ingleses, siendo respaldado en esta empresa por el rey de Francia, Felipe III ${ }^{83}$, al que apoyaría a su vez formando parte de las tropas francesas que actuaron en tierras navarras durante la guerra de la Navarrería, como hemos comentado en líneas anteriores, además de apoyar las aspiraciones al ducado de Aquitania del rey de Castilla, Alfonso X, al que también prestó homenaje ${ }^{84}$, sin dejar, en ningún caso, de recibir el pago de diversas rentas por parte del erario inglés ${ }^{85}$. Todo ello, unido a sus acertadas estrategias matrimoniales y a su extensa red de alianzas hace de este personaje un espejo -algo magnificado, eso sí, debido a la extensión y la importancia de los espacios sobre los que ejercía su poder- de las aspiraciones de la aristocracia que se localizaba entre los Pirineos y el Adour.

\section{EL POSICIONAMIENTO DE LAS ELITES RECTORAS ULTRAPIRENAICAS DENTRO DE LOS CUADROS MILITARES Y ADMINISTRATIVOS DEL REINO DE NAVARRA}

En cualquier caso, el triunfo de la opción francesa frente a las arboladas por la aristocracia navarra peninsular implicó también el triunfo de la estrategia de las elites ultraportanas, que irían ascendiendo progresivamente en la escala social navarra hasta acceder al estatus más elevado, el de ricohombre. Por otro lado, y como se explicará posteriormente, a partir de este momento los ultraportanos comenzaron a posicionarse en ciertos puestos administrativos en el territorio navarro.

Hay que recordar que pocas familias ultraportanas lograron izarse hasta la ricohombría, pero el porcentaje resulta notable, teniendo en lugar que se trata de un grupo restringido, que en un principio se ceñía a un número simbólico -12, en referencia a los doce apóstoles ${ }^{86}$ — pero que oscilaba entre esta cifra y la quincena ${ }^{87}$. En 1329, los datos procedentes de la coronación de Felipe y Juana desvela-

81 Véase TUCOO-CHALA, P.: La vicomté de Béarn et le problème de sa souveraineté, Bordeaux, Bière, pp. 62 y ss.

${ }^{82}$ Como al vizconde de Soule o al de Tartas en 1247 (documento transcrito por GARCÍA ARANCÓN, M. ${ }^{a}$ R., AGN, op. cit., doc. 27, p. 27).

${ }^{83}$ La correspondencia sobre este problema entre Eduardo I y Felipe III se conserva en TNA, SC 1/55, n. 6 y el perdón final inglés de 1279 en RYMER, T., op. cit., tomo II, p. 133.

${ }^{84}$ Del que fue liberado en 1259 (ADPA, E 288).

8513 libras esterlinas al día en 1242, según P. TUCOO-CHALA: op. cit., p. 60 y apéndice documental, n. -10 , p. 151 y aún cobraba ciertas rentas en 1284 «Mandamus vobis quod illas quinquaginta libras burdegalensium quas dilectus et fidelis noster Gasto, vicecomes Biarnensis, assignavit Garsioni de Marchia, militi, percipiendas annuatim de feodo quod eidem Gastoni debemus" (Ch. BÉMONT: Roles gascons..., tomo II, p. 283, doc. 954).

${ }_{86}$ Relacionado también con una simbología numérica relativa a lo completo, a lo perfecto, según comenta PASTOREAU, M.: Une histoire symbolique du Moyen Âge occidental, Paris, Du Seuil, 2004, p. 27.

${ }^{87}$ Veáse RAMÍREZ, E.: «La nobleza bajomedieval navarra: pautas de comportamiento y actitudes» en La nobleza peninsular en la Edad Media. Congreso de Estudios Medievales. León 1997, pp. 297-324. 
ban a 2 ultraportanos entre la lista de ricoshombres, en concreto Arnaldo Guillermo, señor de Agramont y Guillermo Arnaldo, señor de Sault ${ }^{88}$. Sin embargo, varios años después, con Carlos II en 1350, la relación aumentó hasta representar un tercio de los asistentes, con el señor de Agramont de nuevo, junto con otro pariente, Arnaldo Ramón de Agramont; el señor de Luxa y el señor de Ahaxe - que a priori no constituía una de las familias más relevantes del panorama ultraportano- cobrando todos ellos una importancia notable a partir de ese momento ${ }^{89}$.

Otro de los resultados fue, como ya se ha comentado, la progresiva «invasión» por parte de la mediana y pequeña aristocracia ultraportana de los cargos reales navarros, tanto en tierras peninsulares como más allá de los Pirineos. En los cuadros siguientes se detallan los cargos que ocuparon hasta 1328 según los registros contables. Lo primero que salta a la vista es que, a pesar de la variedad de puestos detallados, estos se ceñían a un número reducido de grupos familiares, por ejemplo los de Garro, Mauleón, Ezpeleta, Irumberri, Urtubia y Agramont (ver Tablas I a III). Todos ellos resultaban piezas fundamentales en el esquema de dominación de los Capetos. Los Agramont controlaban las parroquias fronterizas con el Béarn, mientras que los Mauleon habían intercambiado su señorío en Soule, pero aún representaban un argumento de peso que esgrimir contra el monarca inglés. Por su parte, tanto los Garro, los Ezpeleta y más aún, los Urtubia ${ }^{90}$, se encontraban en territorio labourdino, de modo que a través de este servicio los monarcas franceses los arrancaban, o al menos los alejaban, de la influencia inglesa. Del mismo modo, las listas de mesnaderos estaban repletas de pequeños nobles labourdinos que se inclinaban por el bando navarro, como se puede ver cristalizado en las reclamaciones inglesas que se presentaron tras el conflicto de $1244^{91}$.

La presencia de los ultraportanos en los cuadros peninsulares, sobre todo como tenentes de los castillos navarros, sufrió un notable impulso durante los años 1315-1320 (Ver Tabla II). En este momento, mientras Eduardo II se encontraba volcado en imponer su autoridad sobre los territorios aquitanos tras el fracaso de las campañas escocesas, los monarcas franceses ya se hallaban asentados en el trono, y por tanto podían fomentar las aspiraciones de estos grupos aristocráticos que les habían prestado un apoyo continuado. Por el contrario, durante los

88 AGN, Comptos, caj. 6, n.ำ 60 .

89 ZABALO, J.: La administración del reino de Navarra, pp. 210-213.

90 Sus tierras patrimoniales se encontraban cercanas a la costa labourdina, en los alrededores del puerto de San Juan de Luz, y emparentaron con la casa de Sault, como cita Lope García de Salazar «Fállase por memoria de los antepasados, e aun por algunos escrituras, qu'el solar de Urtubia es mucho antiguo e poderoso en aquella tierra de Laborte e fue suçedido del solar de Caldua, que es en el señorío de aquella tierra. E este solar de Caldua, que ellos llaman Saot, fue fundado de un fijo del Señor de Lebred, que es un grand señor en el ducado de Guiana» (GARCÍA DE SALAZAR, L., Bienandanzas e Fortunas, Libro XXI, ejemplar electrónico http://parnaseo.uv.es/lemir/textos/bienandanzas/libros/libro21. htm, consulta 30/01/2013).

91 Reclamaciones que se desgranaron en un documento excepcional del AGN (Comptos, caj. 5, n. 39, I-IV transcrito por CIÉRBIDE, R.: «La encuesta cuatriligüe de 1249», Príncipe de Viana, n.ำ 212 (1997), pp. 521-556. 
primeros años de la presencia capeta, se puede observar una proliferación de castellanos procedentes de otras regiones francesas, lo cual respondía a una estrategia concreta de estos monarcas, decididos a no dejar en manos de la aristocracia navarra, que se había opuesto a su coronación, dichas infraestructuras castrales $^{92}$. De este modo, el apoyo de los señores ultraportanos les resultaba crucial para contrarrestar esta influencia.

Tabla I: Miembros de la aristocracia autóctona nombrados castellanos en ultrapuertos $^{93}$

\begin{tabular}{|l|l|c|}
\hline \multicolumn{1}{|c|}{ Localidad } & \multicolumn{1}{c|}{ Nombre } & Fecha \\
\hline \multirow{2}{*}{ San Juan de Pie de Puerto } & Arnaldo, señor de Irumberri & 1309 \\
\cline { 2 - 3 } & Ramón Arnaldo de Salha & 1318 \\
\hline \multirow{2}{*}{$\begin{array}{l}\text { La Nau Peciada (y el monte de } \\
\text { Garraheguia) }\end{array}$} & Arnaldo de Garro & 1300 \\
\cline { 2 - 3 } & Johan de Mauleón & 1313 \\
\hline Mondarrain & Bernardo de Garro & $1305-1307$ \\
\hline Montferrand & Sancho Arnaldo de Ezpeleta & $1283-1286$ \\
\hline ( medio año) & Arnaldo, señor de Irumberri & 1309 \\
\hline Rocabruna (años sucesivos) & Ramón Arnaldo de Mauleón & $1307-1321$ \\
\hline \multirow{2}{*}{ Rocafort (y la casa de Arberoa) } & Pedro Arnaldo de Saint Pée & 1291 \\
\cline { 2 - 3 } & García Arnaldo de Saint Pée & 1294 y $1 / 2$ año \\
\cline { 2 - 3 } & Ramón Arnaldo de Mauleón & 1307 \\
\cline { 2 - 3 } & Bernard de Saint Palais & 1309 \\
\hline
\end{tabular}

Tabla II: Miembros de la aristocracia ultraportana como castellanos en la Navarra continental

\begin{tabular}{|l|l|c|}
\hline \multicolumn{1}{|c|}{ Localidad } & \multicolumn{1}{c|}{ Nombre } & Fecha \\
\hline Castillos merindad de Pamplona & Arnaldo, señor de Irumberri & 1300 \\
\hline Belmercher & Arnaldo, señor de Irumberri & $1305-1306$ \\
\hline Caseda y Santacara & Brasco García, señor de Luxa & 1280 \\
\hline Estella & Arnaldo, señor de Irumberri & 1312 \\
\cline { 2 - 3 } & $\begin{array}{l}\text { Oger de Irumberri, hermano } \\
\text { del señor de Irumberri }\end{array}$ & 1312 \\
\hline
\end{tabular}

92 Por ejemplo, Pons de Montrodat, que fue merino de Pamplona, o los castellanos Pierre Diable, Pierre de Besançon, Roberto de Senlis o Aymar de Villiers entre otros, procedentes del norte de Francia.

93 Todos los datos que aparecen en estas tablas han sido extraídos de la serie de registros contables reales navarros, cuyos originales se custodian en el AGN, y han sido transcritos en la colección AVRN, tomos II al XI. 


\begin{tabular}{|c|c|c|}
\hline Localidad & Nombre & Fecha \\
\hline \multirow[t]{2}{*}{ Falces } & Bernardo de Saint Palais & $1321-1325$ \\
\hline & Arnaldo, señor de Irumberri & 1304 \\
\hline \multirow[t]{2}{*}{ Gorriti } & Arnaldo, señor de Irumberri & $1300-1304$ \\
\hline & $\begin{array}{l}\text { Pedro Arnaldo de Urtubia (con } \\
\text { Johan de Urroz) }\end{array}$ & 1321 \\
\hline \multirow[t]{2}{*}{ Irulegui (y Castelnuevo) } & $\begin{array}{l}\text { Arnaldo Guillermo, señor de } \\
\text { Agramont }\end{array}$ & $1280-1282$ \\
\hline & $\begin{array}{l}\text { García Arnaldo de Saint Pée, } \\
\text { ballestero }\end{array}$ & 1290 \\
\hline Irurita & $\begin{array}{l}\text { Pedro Arnaldo de Urtubia (con } \\
\text { Johan de Urroz) }\end{array}$ & 1321 \\
\hline Laguardia & $\begin{array}{l}\text { Oger de Agramont (con Dru de } \\
\text { Saint Pol) }\end{array}$ & 1321 \\
\hline Lana, cuevas de & Guillermo de Bigorra & 1291 \\
\hline Larraga & Sancho de Lizarazu & 1325 \\
\hline Leitza & $\begin{array}{l}\text { Pedro Arnaldo de Urtubia (con } \\
\text { Pedro Martínez de Beraiz, Johan } \\
\text { de Garriz) }\end{array}$ & 1321 \\
\hline \multirow[t]{2}{*}{ Lerin } & García Arnaldo de Saint Pée & $1304-1306$ \\
\hline & García Sánchez de Ezpeleta & $1316-1325$ \\
\hline Lumbier & Ichusco de Garro & 1280 \\
\hline \multirow[t]{2}{*}{ Maya } & Arnaldo, señor de Irumberri & $1307-1309$ \\
\hline & Señor de Saut & $1311-1321$ \\
\hline \multirow[t]{4}{*}{ Orzorrotz } & Ichusco de Garro & 1280 \\
\hline & Bernardo de Garro & 1283 \\
\hline & Pedro de Ezpeleta & $1291-1294$ \\
\hline & Pedro Arnaldo de Urtubia & $1316-1321$ \\
\hline \multirow[t]{2}{*}{ Toro } & Oger de Irumberri & 1313 \\
\hline & Arnald, señor de Irumberri & 1311 \\
\hline
\end{tabular}

Tabla III: Miembros de la aristocracia ultraportana en puestos relevantes de la Administración navarra: merinos, bailes

\begin{tabular}{|l|l|c|}
\hline \multicolumn{1}{|c|}{ Cargo } & \multicolumn{1}{c|}{ Nombre } & Fecha \\
\hline Almirante del Roncal y Salazar & Bertrand Jourdain de l'Isle & $1293-1294$ \\
\hline Merino de Estella & Arnaldo, señor de Irumberri & $1311-1312$ \\
\hline Merino de las Montañas & $\begin{array}{l}\text { Pedro Arnaldo de Urtubia (con } \\
\text { Johan López de Urroz) }\end{array}$ & 1321 \\
\hline Baile de Arberoa & Bernard de Saint Palais & 1309 \\
\hline
\end{tabular}




\begin{tabular}{|l|l|c|}
\hline \multicolumn{1}{|c|}{ Cargo } & \multicolumn{1}{c|}{ Nombre } & Fecha \\
\hline $\begin{array}{l}\text { Baile de la bastida de Echarri, } \\
\text { Burunda, Aranaz y Araquil }\end{array}$ & Oger de Mauleón & 1312 \\
\hline Baile de Labastide Clairence & Raymond de Ahaxe & 1321 \\
\cline { 2 - 3 } & Ramón Bernard de Saint Palais & 1317 \\
\hline Baile de Ultrapuertos & Arnaldo, señor de Irumberri & $1309-1313$ \\
\cline { 2 - 3 } & Johan de Mauleon & $1310-1313$ \\
\hline $\begin{array}{l}\text { Guarda del bosque de Garrare- } \\
\text { guía }\end{array}$ & Ramón Bernard de Saint Palais & 1309 \\
\hline Inquisidor en Navarra & Señor de Navailles & 1307 \\
\hline $\begin{array}{l}\text { lugarteniente del gobernador en } \\
\text { Navarra }\end{array}$ & Bertrand Jourdain de l'Isle & 1291 \\
\hline Portavoz del rey ${ }^{94}$ & Señor de Agramont & 1284 \\
\hline Portavoz del rey & Pedro Arnaldo de Luxa & 1285 \\
\hline Procurador de Ostabares & Bernardo, señor de Laxague & 1318 \\
\hline Procurador de Ostabares & Pedro Arnaldo, señor de Berraute & 1318 \\
\hline Recaudador del tributo en Arberoa & García Arnaldo, señor de Belzunce & 1318 \\
\hline Recaudador del tributo en Baztán & $\begin{array}{l}\text { Guillem Arnaldo, señor de Saut } \\
\text { Ostabares }\end{array}$ & 1313 \\
\hline
\end{tabular}

No se pueden olvidar los ingresos que obtenía la aristocracia a través del servicio militar al monarca navarro. La lista de mesnaderos ultraportanos resulta muy extensa y variada, oscilando en cuanto a cantidades percibidas desde las 100 libras que cobraban los señores de Mauleón, Luxa o Agramont en 1293 ${ }^{95}$, las 40 libras que recibía García Arnaldo, señor de Garro, un año después ${ }^{96}$ o las 20 libras que cobraban los titulares de Belzunce o de Uharte Juson ${ }^{97}$. Por tanto, la distinción social en el seno de esta aristocracia se identificaba también a través de la contabilidad real, ya que los titulares de los señoríos más importantes recibían lo que se denominaba como «mesnadas de barones», además de diversos honores sobre distintas tierras o rentas del rey, como ocurría en el caso de Oger de Mauleón ${ }^{98}$. Sin embargo, este comportamiento resultaba minoritario, ya que lo que abundaban en las filas navarras eran los representantes de la pequeña aristocracia ultraportana y labourdina, como los ya mencionados Belzunce, Garro, Laxague, Irumberri o

\footnotetext{
94 «con los vascos» (Otra denominación otorgada a los gascones bajo el dominio del rey de Inglaterra) en Bonloc.

95 AVRN, Tomo IV, 2000, p. 469.

96 Ídem, p. 474.

97 AVRN, Tomo VI, p. 373.

98 AVRN, Tomo V, p. 228.
} 
Sault de Ostabares, aunque también se podían localizar grandes familias como los Agramont o los Mauleón ${ }^{99}$. Se puede concluir por tanto que el servicio militar al monarca navarro aportaba a la mediana aristocracia ultraportana unos ingresos anuales que les permitían mantener un estatus social determinado y acceder a ciertos cargos relevantes ${ }^{100}$.

Los beneficios que estos grupos aristocráticos de tipo medio habían obtenido están claros, sin embargo, aún restaba identificar las actitudes de la pequeña aristocracia que se encontraba diseminada a lo largo de este territorio ultraportano. Su seguimiento es una tarea más ardua, ya que el rastro que han dejado estos grupos en la documentación es débil. Por tanto, no es posible establecer pautas tan marcadas como para los nobles mencionados en las líneas anteriores para ser capaces de poner de relieve su actuación frente a los intentos de control del poder navarro.

En primer lugar, un obstáculo que destaca Susana Herreros en su estudio sobre tierras ultraportanas respecto a este grupo aristocrático es precisamente su alta concentración, sobre todo en tierras de Cisa. De hecho, la costumbre de los valles cisanos y de Osses establecía que una persona que adquiriera una tierra infanzona o se uniera en matrimonio a una casa noble podía conseguir la elevación de su estatus al de la tierra ${ }^{101}$. Así ocurrió en el caso de Pedro Arnaldo de Beorlegouy, que a finales del siglo XIV que tras su matrimonio pasó a formar parte de la casa de Basaburua ${ }^{102}$.

En cualquier caso, de nuevo a través de los registros contables del reino de Navarra es posible realizar una aproximación - aunque bien es cierto que a través de información sesgada - al posicionamiento de los grupos bajonobiliarios respecto al poder real. Y el resultado resulta, cuanto menos, sorprendente.

En efecto, se pueden discernir dos pautas de comportamiento que podrían parecer opuestas, pero que en realidad se desarrollaron en paralelo. En primer lugar, ya se ha comentado que la pequeña aristocracia ultraportana constituía uno de los componentes principales del aparato militar navarro ${ }^{103}$. Hasta aquí no encontramos ningún factor novedoso, ya que se trata de un comportamiento que se reproducía en las capas más modestas del estamento aristocrático en otros terri-

\footnotetext{
99 Las listas se repetían en años sucesivos, ver por ejemplo AVRN, tomo X, p. 257 e incluían en ocasiones a varios miembros de un grupo familiar.

100 Para una lista completa de los mesnaderos ultraportanos en 1329, veáse el artículo de I. MUGUETA, «Acciones bélicas en Navarra...» op. cit., p. 76 (apéndices).

101 HERREROS, S.: op. cit., 1998, p. 226.

102 Esta denominación reafirma la idea que ya se ha comentado anteriormente de los topolinajes y de la importancia del solar de procedencia (AVRN, Tomo IV, p. 40, que transcribe el doc. de AGN, Comptos, caj. $31, \mathrm{n} . \stackrel{\circ}{4}$, fol. 14 r.).

103 Respecto a la implicación de la aristocracia navarra en el aparato militar, se puede consultar el artículo de MUGUETA, I.: «La nobleza en Navarra (siglos XIII-XIV): una identidad militar», lura vasconiae,

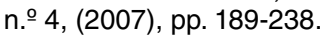


torios circundantes ${ }^{104}$. Sin embargo, a la vez que se registraban estas referencias al servicio real, la documentación contable real está trufada de menciones constantes y sistemáticas a enfrentamientos que se podrían calificar de «privados» - aunque por desgracia se desconocen los motivos en su mayor parte- y de problemas con los agentes reales navarros. Por tanto, este detalle permite matizar esta colaboración militar y encuadrarla dentro de un territorio en constante movimiento y con una conflictividad latente que se desvela en estos registros.

Los primeros en darse cuenta fueron los propios agentes navarros, como se traslucía de un documento emitido en 1258 por senescal de Navarra dirigido los territorios ultraportanos bajo control directo del monarca, esto es, Cisa, Baigorry, Osses, Iholdy y Armendáriz ${ }^{105}$, en el que se ordenaba que:

«Et otrossi los cauaylleros et los yfançones si mal se quisieren fazer l'un a l'otro que se desafidien en mercado, a die de mercado, en Sant Johan, ante l'alcalde de Cieysa, et deuant dos cauailleros et dos yfançones al menos, et dent ata 10 dias que no'l faga mal et qui d'otra maneyra matar si no fuesse en batailla suddosa, que sea traidor. Et por guerra ninguna que non se roban ni ardan.»106.

Parece claro que el representante del rey había identificado ciertas actividades de violencia privada en estas zonas e intentaba canalizarlas y controlarlas a través de duelos regulados por el baile de Cisa. Del mismo modo, el documento establecía la prohibición de circular con un acompañamiento armado excesivo, de lo que se deducía precisamente que dicha amenaza resultaba constante, fomentando con ello las expresiones de violencia privada.

El control del monarca navarro sobre los territorios ultraportanos se cristalizaba también a través de sus prerrogativas de justicia reflejadas en su vertiente recaudatoria, esto es, en el apartado de las multas consignadas por los agentes reales. Si nos acercamos un poco más a los registros contables, como se puede ver en la tabla que aparece a continuación, la recaudación derivada de los conflictos entre dos señores, si bien representaba en sí misma una cantidad poco relevante - con cifras que abarcaban de los 3 a los 20 sueldos-, resultaba uno de los motivos mencionados con mayor asiduidad en las multas contenidas dentro del epígrafe dedicado a las tierras navarras más allá de los Pirineos.

Estas cifras traslucian por tanto una conflictividad constante de tipo privado. Dichos enfrentamientos se producían en su mayor parte entre representantes de la pequeña aristocracia, que en muchas ocasiones ni siquiera se identificaban

104 Uno de los estudios más relevantes sobre la baja nobleza es el de DíAZ DE DURANA, J. R.: La otra nobleza. Escuderos e hidalgos sin nombre y sin historia. Hidalgos e hidalguía universal en el País Vasco al final de la Edad Media (1250-1525), Bilbao, UPV-EHU, 2004; para una panorámica más extensa dirigirse al artículo de PASTOR, R. ; ESTEPA, C., ALFONSO, I.; ESCALONA, J.; et al.: «Baja nobleza: aproximación la historiografía europea y propuestas para una investigación», Historia social, n.ㅇ 20 (1994), pp. 23-45

105 Las tierras de Mixa y Ostabares dependían del señor de Tartas, al igual que las parroquias de la frontera norte, dependientes del señor de Agramont.

106 AGN, Comptos, caj. 3, n.ำ 10, transcrito por GARCÍA ARANCÓN, M.ํㅡ. R., AGN, op. cit., doc. 41. 
nominalmente, simplemente por su patronímico ${ }^{107}$, y se desarrollaban en su mayor parte en un marco local o entre parroquias colindantes (ver Tabla IV). Por desgracia, al tratarse de documentos contables, en la mayor parte de los casos no aparecían registrados los motivos de la disputa, aunque siguiendo el patrón de cercanía territorial de los señores implicados, se podría aventurar cierta relación con un patrimonio fundiario contestado - derivado de problemas de delimitación de los espacios o de herencias-. También se podían localizar conflictos derivados de antiguas alianzas, como ocurrió en el caso de los señores de Villanueva e Iribarren, en la zona de Osses, que se presentaron como garantes del señor de Exhava de Echeverria, en la misma zona, y al no cumplir este último sus compromisos se vieron involucrados en su deuda ${ }^{108}$.

En cuanto a los resultados de la violencia imperante, se puede constatar que pocos homicidios han quedado plasmados en las cuentas reales. Sólo localizamos algunos casos investigados, como el de Arnaldo de Ahaxe, que mató a Aner de Etxaondo y para el cual se estableció una multa de 30 sueldos en $1294^{109}$, o la muerte del señor de Irigoyen de la parroquia de Heleta, en el valle de Arberoa, de la que no se tienen noticias ni siquiera del culpable. Por su parte, en 1314, el señor de Echart fue multado con 15 sueldos por haber herido a Bernardo de Alcurrun ${ }^{110}$. Sin embargo, estas actividades resultas irrisorias comparadas con los ataques que se producen en períodos de gran conflictividad, como puede ser la guerra anglo-navarra que se desarrolló durante los años 40 del siglo XIII. En ese momento los pequeños nobles ultraportanos aprovecharon para realizar verdaderas razzias, en ocasiones contra sus propios vecinos, de cara a obtener beneficios tangibles derivados sobre todo del robo de ganado o de la obtención de rehenes ${ }^{111}$.

Tabla IV: Enfrentamientos privados entre aristócratas ultraportanos ${ }^{112}$

\begin{tabular}{|l|l|c|}
\hline \multicolumn{1}{|c|}{ Implicado 1 } & \multicolumn{1}{c|}{ Implicado 2 } & Fecha \\
\hline Señor de Meharin (Arberoa) & Merino del reino de Navarra & 1304 \\
\hline Señor de Alzu (Cisa) & Ramón Aymeric & 1305 \\
\hline Señor de Alzu (Cisa) & Hospital San Miguel el Viejo (Cisa) & 1316 \\
\hline Señor de Apata (Cisa) & María López Echepare & 1318 \\
\hline Señor de Çaro (Cisa) & Bernet de Faret & 1306 \\
\hline
\end{tabular}

107 Pudiendo constituir un signo de la importancia del topolinaje, un concepto procedente de la antropología y desarrollado, entre otros, por Michel Lauwers, Didier Méhu, Dominique logna-Prat, Anita Guerreau-Jalabert, Alain Guerreau o Joseph Morsel.

108 AVRN, Tomo VII, p. 697.

109 AVRN, Tomo IV, p. 449.

110 AVRN, Tomo IX, p. 635.

111 Para referencias concretas, ver el artículo de APARICIO, S.: «La violencia en Gascuña y los enfrentamientos anglo-navarros (siglos XIII y XIV)", Huarte de San Juan. Geografía e Historia, n. 14 (2007), pp. 9-31 y el ya citado de VINCENT, N.: «A Forgotten War...», op. cit.

${ }_{112} \mathrm{Al}$ igual que las tablas anteriores, esta se alimenta de los registros contables navarros, en concreto del apartado de calonias, que fueron transcritos en la serie de los AVRN. 


\begin{tabular}{|c|c|c|}
\hline Implicado 1 & Implicado 2 & Fecha \\
\hline Señor de Echeverría (Cisa) & Señor de Suescun (Cisa) & 1305 \\
\hline Señor de Eligueta Juzon (Cisa) & Hija de la casa de Eligueta (Cisa) & 1318 \\
\hline Señor de Elque de Bustinza (Cisa) & Hijo de Menaud de Ahaxe (Cisa) & 1307 \\
\hline Señor de Espilla (Cisa) & Señor de Echaondo & 1318 \\
\hline Señor de Ganaberro (Cisa) & Bergoin de Arbelbide & 1305 \\
\hline Señor de Ganaberro (Cisa) & Señor de Arrozbide (Cisa) & 1306 \\
\hline Señor de Helizeche (Cisa) & Bernardo de Fayet & 1305 \\
\hline Señor de Irigay (Cisa) & Señores de Irigoyen (Cisa) & 1305 \\
\hline Señor de Issaraute (Cisa) & Aner de Ugange (Cisa) & 1306 \\
\hline Señor de Iturriaga (Cisa) & Martín Barbero & 1305 \\
\hline Señor de Iturriaga (Cisa) & Señor de Ganaberro (Cisa) & 1306 \\
\hline Señor de Iturriayçeta (Cisa) & Señor de Recalde de Bussunaritz (Cisa) & 1307 \\
\hline Señor de Iturriti de Lacarra (Cisa) & Señor de Apata (Cisa) & 1318 \\
\hline Señor de la Peyra de Latarçe (Cisa) & Señor de Zaparrat (Cisa) & 1318 \\
\hline Señor de Lasa (Cisa) & Johan López & 1306 \\
\hline Señor de Latarçe Echeverri (Cisa) & Clavero de Ahaxe (Cisa) & 1318 \\
\hline Señor de Latseta (Cisa) & Raimundo Arnaldo de Escos & 1318 \\
\hline Señor de Lavayru (Cisa) & Johan, tendero & 1306 \\
\hline Señor de Ligueta Juzon (Cisa) & Señor de Iturriaga (Cisa) & 1306 \\
\hline Señor de Lizondo (Cisa) & Señor de Ganaberro (Cisa) & 1306 \\
\hline Señor de Socarro de Zabalza (Cisa) & Señor de Laborda (Cisa) & 1316 \\
\hline Señor de Suescun (Cisa) & Señor Brasc de Vilanova & 1305 \\
\hline Señor de Urrutia de Suescun (Cisa) & Señor de Iriarte (Cisa) & 1307 \\
\hline $\begin{array}{l}\text { Señor de Echepare (Iholdy-Armen- } \\
\text { dariz) }\end{array}$ & $\begin{array}{l}\text { García de Mendicoagua, capellán de } \\
\text { Osses }\end{array}$ & 1307 \\
\hline $\begin{array}{l}\text { Señor de llçaurgarat (Iholdy/Ar- } \\
\text { mend.) }\end{array}$ & $\begin{array}{l}\text { García de Mendicoagua, capellán de } \\
\text { Osses }\end{array}$ & 1307 \\
\hline Señor de Olzo (Iholdy y Armendáriz) & Señor de Arrecart (Iholdy y Armendáriz) & 1305 \\
\hline Sancho de Lacarra (Iholdy/ Arm.) & Señora de Armendáriz & 1305 \\
\hline Señor de Beguios (Mixa) & Señor de Meharin (Arberoa) & 1304 \\
\hline Sr. de Echava de Echeverría (Osses) & Johan Zaldaqui & 1307 \\
\hline Sr. de Echava de Echeverría (Osses) & Johan del Portal y Johan Zaldaqui & 1306 \\
\hline Sr. de Exhava de Echeverría (Osses) & Señor de Villanueva (Osses) & 1307 \\
\hline Señor de Echeverry (Osses) & Johan Çaldaqui & 1307 \\
\hline Señor de Irivarren de Ahayz (Osses) & Señor de Exhava de Echeverría (Osses) & 1307 \\
\hline
\end{tabular}


En el caso de las familias de mayor importancia dentro del cuadro ultraportano, el hecho de tener ciertos cargos dentro del entramado administrativo navarro no les eximía de fomentar un control lo más amplio posible sobre el territorio, y enfrentarse a aquellos otros grupos que amenazaran su hegemonía en la zona. Los episodios de violencia privada se sucedían, por ejemplo, entre los señores de Luxa y Agramont, aunque esto no les impidió asociarse en 1314 para atacar ciertas parroquias en Mixa ${ }^{113}$, del mismo modo que el señor de Agramont acompañó a sus aliados de Béarn en un ataque a los francos dependientes del rey navarro en Escos durante el año $1309^{114}$. Esta misma familia tendrá también un encontronazo con los condes de Foix, que en 1307 enviaron un destacamento para atacar las tierras agramontesas, con el resultado de la muerte de dos hombres en Bergouey, que sería investigada por los agentes navarros ${ }^{115}$.

También es posible localizar ciertos ejemplos de la contestación directa al control real, sobre todo en las tierras de los vizcondes de Tartas. En 1293 debieron hacer frente a un juicio ante la Cort de Navarra, en el que se les acusaba, entre otras cosas, de haber derribado sin permiso la fortaleza de Villanueva, para poder utilizar las piedras restantes en una nueva fortificación ${ }^{116}$. Además se afirmaba que cobraban ciertos peajes arbitrarios y no autorizados por el monarca navarro ${ }^{117}$. El problema de los peajes exigidos por los nobles ultraportanos no es un tema nuevo, el propio Codex Calixtinus ya acusa al señor de Agramont y a otros nobles de la zona de establecer prácticas abusivas a este respecto ${ }^{118}$. En otro orden de cosas, Amanieu, señor de Albret, que había heredado las tierras de Tartas, y por tanto ejercía su autoridad sobre las tierras de Mixa y Ostabares entró en conflicto en 1318 con el castellano de San Juan de Pie de Puerto, ya que al parecer impartía justicia en Garris sin la presencia del representante real, el baile de Mixa ${ }^{119}$.

Ante estas actitudes de contestación la respuesta de los agentes reales solía ser la de establecer una encuesta o intentar obtener algún tipo de acuerdo de mediación, como en el caso de los señores de Luxa y Agramont, que en 1318 resolvieron sus querellas y prometieron ceñirse a la autoridad regia navarra ${ }^{120}$. De este modo, el monarca aparecía también en su papel de árbitro en los enfrentamientos, una forma de afirmar su poder sobre el territorio. Sin embargo, en un

${ }^{113}$ AVRN, Tomo IX, p. 641.

${ }^{114}$ AVRN, Tomo VIII, p. 290.

${ }^{115}$ AVRN, Tomo VII, pp. 700-701.

${ }^{116}$ La construcción de fortalezas —o la destrucción de las mismas— había de ser sometida al consentimiento regio.

${ }^{117}$ AVRN, Tomo IV, p. 42.

118 «Exigimos y rogamos ardientemente que estos recaudadores, juntamente con el Rey de Aragón y demás personas acaudaladas que de ellos reciben el dinero de los tributos, así como aquellos que lo consienten, como son Raimundo de Soule, Viviano de Agramonte y el Vizconde de San Miguel con toda su descendencia, (...) que sean diligentemente excomulgados" (Codex Calixtinus. Capítulo VII, extracto consultado en http://www.jacobeo.net/index.php?modulo=42 el 18/06/12).

${ }_{119}$ AVRN, Tomo X, p. 433.

120 Ídem, p. 688. 
caso concreto, aunque algo tardío, los monarcas de Navarra sacaron partido precisamente de esta situación de contestación a su poder. Este hecho se produjo en 1338, durante el reinado de Juana y Felipe de Evreux, cuando se confiscó todos los feudos de este vasallo rebelde, el señor de Albret, que al haber entroncado con los vizcondes de Tartas, poseía de las tierras de Mixa y Ostabares ${ }^{121}$ En cualquier caso, este hecho no deja de ser una circunstancia excepcional, dentro de una situación de violencia privada que la administración real navarra intentó fiscalizar y que a pesar de no haber sido encauzada del todo, no resultaba un impedimento para la extensión del control territorial del monarca navarro sobre Ultrapuertos.

Por último, en este capítulo no podemos dejar de mencionar una marca fundamental que nos muestra hasta qué punto estas elites se integraron perfectamente en los cuadros administrativos y militares navarros, pero sus acciones a la hora de establecer una red familiar o de lealtades se encontraban profundamente mediatizadas por su procedencia territorial, fronteriza entre varios reinos y al otro lado de los Pirineos. En efecto, hasta una época bastante tardía -incluso bien entrado el siglo XV- los señores ultraportanos no establecieron lazos ni matrimoniales ni de alianzas duraderas con la aristocracia navarra peninsular. Antes bien, permanecieron siempre ligados a unas redes sociales muy territorializadas en el sur del Adour. De hecho, a pesar de no relacionarse con los navarros peninsulares, sí se pueden localizar varios casos de alianzas con las elites labourdinas. Se puede poner como ejemplo paradigmático a los señores de Agramont, a los que hemos visto prestar homenaje y diversos servicios al rey de Navarra, y a los que se incluía dentro de la lista de ricoshombres navarros. Sin embargo, Arnaldo Guillermo III de Agramont contrajo matrimonio con la señora de Bardos, heredera de este territorio que pasaría a manos agramontesas y por ende a la órbita navarra, aunque se encontraban dentro de la zona inglesa, en el Labourd. Su hermano Auger priorizó por su parte una alianza ultraportana, con la señora de Gabat y Masbarraute. Por su parte, el siguiente señor de Agramont contrajo matrimonio hacia 1312 con Miramonda de Aspremont, emparentada con los señores de Orthe, una familia de obediencia inglesa procedente de la zona de Dax, bastante alejada por tanto de las tierras patrimoniales agramontesas ${ }^{122}$.

\section{BALANCE FINAL}

Como tónica general, se puede afirmar que la pequeña y mediana aristocracia ultraportana vivió en un ambiente de conflictividad latente durante todo el siglo XIII hasta los albores de la Guerra de los Cien Años, que afectó profundamente a la

121 Véase HERREROS, S.: op. cit., 1998, p. 252.

122 GRAMONT, A. A. de, Histoire et généalogie de la Maison de Gramont, Paris, Schlesinger, 1874, p. $5,108$. 
estructura social y al patrimonio fundiario de las elites del sudoeste francés, no sólo en el caso navarro sino también en las tierras francesas e inglesas.

De hecho, no se debe perder de vista que los agentes del rey de Inglaterra también se vieron obligados a hacer frente a esta realidad de indefinición de forma mucho más acentuada desde mediados del siglo XIII. En ese momento, las derrotas sucesivas sufridas por Enrique III en Saintes y Taillebourg y el homenaje prestado a Luis IX por las tierras que controlaba como duque de Aquitania en el marco del Tratado de París provocaron que la aristocracia de la zona del Labourd -y en general de todo el territorio aquitano- contara con el monarca francés como una instancia superior hacia la que podían dirigirse en el caso de disensiones con los ingleses.

Entre otras cosas, la documentación labourdina está llena de referencias a señores rebeldes, a la reticencia ante la recaudación de las rentas reales y a la edificación de fortalezas adulterinas. Por ejemplo, García Arnaldo de Ezpeleta edificó una estructura castral, Arizmendi, destinada a controlar la circulación hacia la zona navarra en la parroquia de Sara ${ }^{123}$. Ante esta situación, el propio Eduardo II de Inglaterra tuvo que encargar ciertas encuestas en distintos territorios -en 1311 para el Labourd- para conocer la extensión del poder regio sobre estos espacios, en la cual se afirmaba que ciertos miembros de la aristocracia labourdina se arrogaba derechos que pertenecían al monarca y no respetando las directrices de los agentes reales ingleses ${ }^{124}$. De este modo, se puede observar una pauta de comportamiento común para las elites del sur del Adour, independientemente de su adscripción, que se acercaba cada vez más a la órbita francesa, y por ende a sus aliados navarros, ante la pérdida de poder del monarca inglés.

Por otro lado, a lo largo de este artículo se ha podido comprobar la integración de la aristocracia ultraportana en los cuadros administrativos y militares del rey de Navarra, además de contar con lazos vasalláticos con el mencionado monarca. Así, aprovecharon los resortes que ponía a su disposición el poder real navarro para obtener beneficios tangibles, ya fuera a través del cobro de mesnadas, la asignación de rentas vitalicias o de la obtención de cargos. Sin embargo, esto no significa que la zona no sea un lugar de fricciones constantes, ya sea a causa de los enfrentamientos anglo-navarros de 1244 y 1266 o bien por los conflictos privados desarrollados entre la beligerante pequeña aristocracia de la zona, y que intentan resolver por su cuenta.

${ }^{123}$ Véase la referencia en BEMONT, Ch.: op. cit., Tomo II, p. 517: «In parrochia de Sare, in loco qui vocatur Arizmendi».

${ }_{124}$ AMB, DD 20 (copia 1566), transcrito por LAFOURCADE, M.: «La féodalité en Labourd. Enquête ordonnée par Edouard II d'Angleterre pour connaître ses droits sur cette terre. 1311 » en Eugène Goyheneche. Omenaldia-Hommage, San Sebastián, Eusko Ikaskuntza, 2001, pp. 165-179. Los testimonios variaban, pero se especifica que el señor de Ezpeleta han fomentado ciertos núcleos de población sin autorización regia, del mismo modo que el señor de Sault de Hasparren, el de Lahet y el de Pagandurua. Del mismo modo, el señor de Sault y el de Pagandurua ejercían la baja justicia en sus parroquias, cuando en el documento se afirmaba que el rey poseía la alta y baja justicia en todas las tierras de Labourd. 
Dicha conflictividad privada no resultaba un obstáculo para las declaraciones de lealtad al rey de Navarra ni para la progresiva entrada a su servicio de esta aristocracia, sobre todo a partir de la presencia en el trono navarro de monarcas del norte de los Pirineos, como la familia champañesa. Esta situación servirá a su vez para que los monarcas navarros asienten un control territorial y una red de lealtad efectiva en Ultrapuertos.

Sin embargo, a pesar de esta progresiva colaboración, los aristócratas ultraportanos orientaron sus estrategias matrimoniales y sus redes de alianzas de modo que no llegaban a cruzar la barrera pirenaica, extendiéndose hacia zonas fronterizas del Labourd, más allá del Adour o hacia tierras bearnesas. En definitiva, no existen entre estos aristócratas y los navarros lazos que vayan más allá de una colaboración meramente circunstancial - su presencia como mesnaderos en el ejército real, por ejemplo-, de modo que no se relacionaron con los grupos aristocráticos navarros peninsulares de forma continuada hasta finales de la Edad Media. 